\title{
Modelagem metalogenética para prospecção de urânio nas rochas do núcleo da Anticlinal Abaíra-Jussiape, Chapada Diamantina, Bahia
}

\author{
Jocilene dos Santos Santana1, Simone Cerqueira Pereira Cruz', Maisa Bastos Abram², \\ Adriano Alberto Marques Martins ${ }^{2}$ \& Johildo Salomão Figueiredo Barbosa ${ }^{1}$
}

\begin{abstract}
Resumo AAnticlinal Abaíra-Jussiape, com orientação NNW-SSE, é uma culminação antiformal do Cinturão de Dobramentos e Cavalgamentos da Chapada Diamantina Ocidental, no Corredor do Paramirim. Em seu núcleo ocorrem tonalitos-granodioritos, álcali-feldspato granito, sienitos a quartzo-sienitos da Suíte Caraguataí, além de granitos da Suíte Jussiape, de idade paleoproterozoica, todos milonitizados. O arcabouço estrutural é marcado por famílias de estruturas compressionais e distensionais. As estruturas compressionais são relativas a duas fases deformacionais distintas, denominadas de $\mathrm{D}_{1}$ e $\mathrm{D}_{2}$. A principal fase deformacional compressional é a $\mathrm{D}_{1}$, dúctil, que está relacionada com a nucleação de zonas de cisalhamento destrais a destral-reversas. A atuação de processos defomacionais e de recristalização sin- $\mathrm{D}_{1}$ envolvendo o plagioclásio e o K-feldspato sugerem condições de temperatura de deformação superiores aos $550^{\circ} \mathrm{C}$. A fase seguinte, $\mathrm{D}_{2}$, é de natureza dúctil rúptil e levou à geração de zonas de cisalhamento reversas. A família distensional é marcada por estruturas da fase $\mathrm{D}_{3}$ e é representada por zonas de cisalhamentos com movimentos normais. O estudo petrográfico levou à identificação de processos de alteração hidrotermal pré- $\mathrm{D}_{1}$, relacionadas com albitização e potassificação das unidades cartografadas, oxidação sin- $\mathrm{D}_{1}$, além de hidratação e saussuritização relacionadas com as fases $\mathrm{D}_{2} \mathrm{e}$ $\mathrm{D}_{3}$. A integração de dados litológicos, petrográficos, estruturais e geofísicos através da aplicação de método de análise espacial incluindo a lógica Fuzzy à luz dos controles estruturais e litológicos de depósitos de urânio já conhecidos do Corredor do Paramirim, levou à identificação de duas áreas promissoras para a pesquisa desse elemento radiativo no núcleo da Anticlinal Abaíra-Jussiape.
\end{abstract}

Palavras-chave: Anticlinal, zona de cisalhamento, modelagem metalogenética, urânio.

\begin{abstract}
Metallogenetic modeling for uranium exploration in rocks of the Abaira-Jussiape Anticlinal nucleus, Chapada Diamantina, Bahia. The NNW-SSE-trending Abaíra-Jussiape Anticlinal is an antiformal culmination of folding and shearing in the Paramirim Corridor of the Western Chapada Diamantina. In its core Paleoproterozoic, mylonitized Caraguataí Suite, tonalites-granodiorites, alkali-feldspar granites, syenites to quartz-syenites and Jussiape Suite granites crop out. Compressional and distensional stresses mark the structural geology of the area. The compressional structures are related to two distinct deformation phases, named D1a and D1b. The main compressional phase is ductile D1a, which is related to the nucleation of dextral to dextral-reverse shearing zones. Deformation and syn-D1a recrystallization involving plagioclase and the $\mathrm{K}$-feldspar suggest deformation temperature conditions above $550^{\circ} \mathrm{C}$. The following phase D2 is of ductilebrittle nature and culminates in reverse shearing zones. The distensional structures correspond to the D3 phase and are represented by frontal shear zones with normal movement. The petrographic study helped identify a pre-D1a hydrothermal alteration process related to albitization and potassification, syn-D1 oxidation process, and hydration and saussuritization related to phases D2 and D3. The integration of lithological, petrographic, structural and geophysical data by means of the logic Fuzzy, plus the existing information regarding structural and lithologic controls of the known uranium mineralization in the Paramirim Corridor, led us to identify two promising areas for radioactive element exploration in the nucleus of Abaíra-Jussiape Anticlinal.
\end{abstract}

Keywords: Anticline, shear zone, metallogenetic modeling, uranium.

INTRODUÇÃ̃ A Anticlinal Abaíra-Jussiape (Cruz 2004, Cruz \& Alkmim 2006) (Fig. 1) representa uma das estruturas dominantes da porção sul do Cinturão de Dobramentos e Cavalgamentos da Chapada Diamantina Ocidental, no Corredor do Paramirim (Alkmim et al. 1993). Essa anticlinal possui orientação NNW-SSE, podendo ser caracterizada como uma culminação antiformal nucleada pelo substrato de rochas cristalinas de idade arquena a paleoproterozoica (Guimarães et al. 2005, Cruz et al. no prelo). A modelagem metalogenética através da análise espacial dos dados na escala 1:100.000 realizada por Guimarães et al. (2005) no núcleo dessa anticlinal permitiu identificar um total de 30 anomalias e delimitar áreas com potencialidade

1 - PPGG - Instituto de Geociências, Universidade Federal da Bahia, Salvador (BA), Brasil. E-mail: jocilenesanttana@yahoo.com.br, simonecruzufba@gmail.com, johildo@cpgg.ufba.br

2 - CPRM - Serviço Geológico do Brasil, Superintendência Regional de Salvador, Salvador (BA), Brasil. E-mail: maisa.abram@cprm.gov.br, adriano1952@gmail.com 


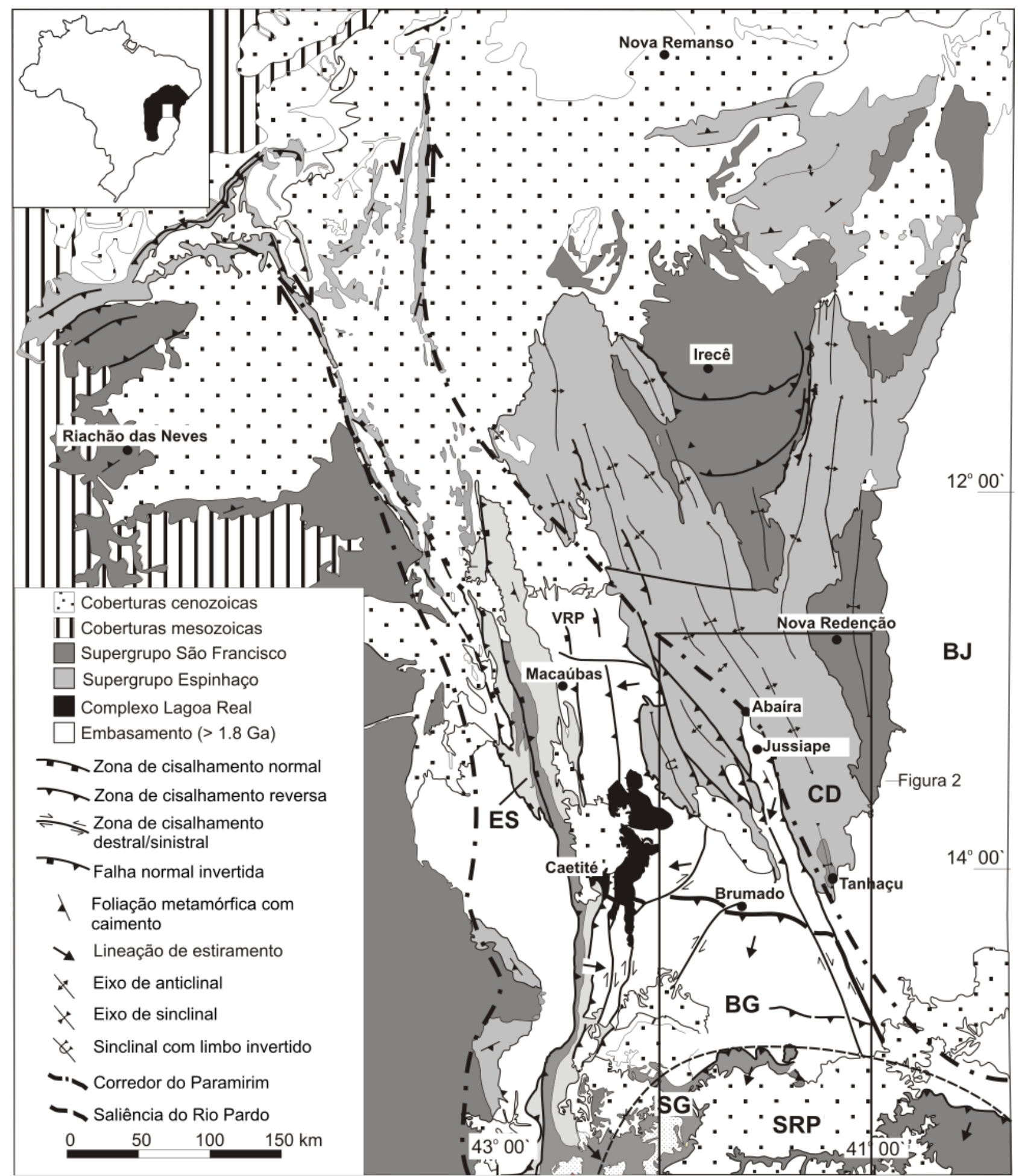

Figura 1 - Mapa Geológico simplificado do Aulacógeno do Paramirim, enfatizando as principais unidades geológicas e estruturas tectônicas de idade brasiliana. BG - Bloco Gavião, BJ - Bloco Jequié, ES - Espinhaço Setentrional, CD - Chapada Diamantina, FRP - Faixa Rio Preto, SRP - Saliência do Rio Pardo (Faixa Araçuai), VRP - Vale do Rio Paramirim e SG - Serra Geral. Mapa construido a partir de Schobbenhaus et al. (1981) e Barbosa \& Dominguez (1996). Fonte: Cruz (2004).

para a presença de mineralizações uraníferas. Nesse sentido, e tendo como base nas paragêneses minerais e contexto geológico associado com a mineralização uranífera do Complexo Lagoa Real (vide Lobato 1985, Maruèjol 1989, Cruz 2004, Chaves et al. 2007), foram levantadas evidências indiretas que sugerem a presença dessa substância no núcleo da anticlinal em foco.

O objetivo do presente artigo é apresentar os resultados da modelagem metalogenética de detalhe (escala 1:25.000) na região de Abaíra-Jussiape com vistas 
a verificar a consistência geológica das anomalias aerogeofísicas de urânio apresentadas por Guimarães et al. (2005). Para a realização da modelagem em foco foram feitos cruzamentos de temas geológicos (litologia, petrografia, estrutural) e geofísicos através de métodos de análise espacial de dados com a aplicação da lógica Fuzzy.

ASPECTOS DA GEOLOGIA REGIONAL A Anticlinal Abaíra-Jussiape posiciona-se tectonicamente no Cinturão de Dobramentos e Cavalgamentos da Chapada Diamantina Ocidental que, por sua vez, está localizada no domínio centro sul do Corredor do Paramirim (Fig. 1). Esse corredor corresponde a uma zona de máxima inversão da feição tectônica denominada originalmente por Moutinho da Costa \& Inda (1982) como Aulacógeno do Espinhaço e posteriormente denominado como Aulacógeno do Paramirim por Pedrosa-Soares et al. (2001). O Corredor do Paramirim (Fig. 1) compreende: (i) rochas arquena/granito-gnáissico-migmatíticas e restos de sequências metavulcano-sedimentar do Bloco Gavião (sensu Barbosa \& Sabaté 2002); (ii) ortognaisses, metassienogranitos a quartzo-sienitos, anfibolitos e albititos mineralizados em urânio do Complexo Lagoa Real (Cruz et. al. 2007), de idade paleoproterozoica (Cordani et al. 1992, Pimentel et. al. 1994, Cruz et al. 2007, dentre outros); (iii) rochas máficas intrusivas, de composição gabronoríticas e de idade meso e proterozoicas (Babinski et al. 1999, Guimarães et al. 2005, Brito 2008, Danderfer et al. 2009); e (iv) rochas metavulcano-sedimentar e metassedimentares do Supergrupo Espinhaço e rochas metassedimentares do Supergrupo São Francisco, de idade paleo/meso e neoproterozoicas, respectivamente (Babinski et al. 1994, Schobbenhaus et al. 1994, Misi \& Veizer 1996).

A evolução tectônica do Corredor do Paramirim é precedida por um período de estruturação do Aulacógeno homônimo, que ocorreu no paleo e mesoproterozoico (Danderfer-Filho \& Dardenne 2002, Guimarães et. al. 2005, Cruz \& Alkmim 2006), cujo modelo de preenchimento é amplamente controverso na literatura se analisados a luz das propostas de empilhamento estratigráfico apresentados por Pedreira (1988), Schobbenhaus (1996), Barbosa \& Dominguez (1996), Danderfer $F^{\circ}$ (2000) e Guimarães et al. (2005), dentre outros. A inversão do Aulacógeno do Paramirim e a estruturação do corredor de deformação homônimo ocorreram no Neoproterozoico (Danderfer-Filho \& Dardenne 2002, Guimarães et al. 2005, Cruz \& Alkmim 2006, Alkmim et al. 2007, Pedrosa-Soares et al. 2007), tendo sido reconhecida por Cruz \& Alkmim (2006) duas fases deformacionais mais importantes, que afetam o embasamento e a cobertura sedimentar. A primeira é marcada por zonas de cisalhamento reversas a reversa-sinistrais e dobras com orientação E-W, ambas com vergência para norte. A segunda corresponde ao conjunto de zonas de cisalhamento e dobras com orientação NNW/SSE que dominam o arcabouço estrutural regional e da Anticlinal Abaíra-Jussiape.

\section{MODELOS GENÉTICOS DA MINERALIZAÇÃO DE URÂNIO NO CORREDOR DO PARAMIRIM}

No Corredor do Paramirim os depósitos de urânio estão hospedados no Complexo Lagoa Real. Os depósitos foram estudados por diversos autores, ressaltando-se os trabalhos realizados por Lobato (1985), Maruèjol (1989), Cruz (2004) e Chaves et al. (2007). A mineralização de urânio é representada por uraninita e pechblenda, que estão hospedadas, preferencialmente, em hematita-aegirina-augita albititos, hematita-andradita-grossularita albititos e em hematita-albititos (Costa et al. 1985, Lobato \& Fyfe 1990, Cruz et al. 2007). Essas rochas estão alojadas em zonas de cisalhamento dúcteis que marcam a fase de inversão do Aulacógeno do Paramirim, no Neoproterozoico (Cruz \& Alkmim 2006).

Os modelos metalogenéticos para a mineralização de urânio no Corredor do Paramirim ainda são controversos. Para Lobato (1985), ela teria sido o produto do metassomatismo sódico-cálcico e de reações de oxidação em zonas de cisalhamento que estruturaram os gnaisses e albititos do Complexo Lagoa Real, ao passo que Maruèjol (1989) defendeu que a mineralização em questão estaria relacionada com a colocação de plútons anorogênicos, que foram posicionados na crosta anteriormente à principal fase de deformação do Complexo Lagoa Real. Para aquela autora, assim como para Caby \& Arthaud (1987), a formação dos albititos mineralizados em urânio reflete o zoneamento do processo de alteração metassomática associada com a colocação dos granitoides desse complexo e que a deformação do estado sólido não contribui com a distribuição da mineralização. Por outro lado, Cruz (2004) defende que a alteração metassomática sódico-cálcica uranífera teria ocorrido anteriormente à estruturação das zonas de cisalhamento do Corredor do Paramirim, de idade neoproterozoica, e que distribuição atual a mineralização estaria controlada pela presença de reações de oxidação que se instalaram durante a nucleação dessas zonas, como também proposto por Lobato \& Fyfe (1990). Recentemente, Chaves et al. (2009) defendem que a mineralização está relacionada com fluidos hidrotermais relacionados com a cristalização de granitoides do Complexo Lagoa Real.

Apesar das controvérsias existentes entre os modelos propostos, é consenso entre os autores a relação entre a mineralização de urânio e as zonas albitizadas, assim como o controle estrutural das zonas de cisalhamento brasilianas na configuração final dos depósitos. Neste sentido, a mineralização de urânio encontra-se associada com domínios miloníticos das zonas de cisalhamento neoproterozoicas do Corredor do Paramirim.

\section{GEOLOGIA DA ÁREA SELECIONADA PARA A MODELAGEM METALOGENÉTICA A área sele-} cionada para a modelagem espacial dos dados corresponde à região indicada por Guimarães et al. (2005) como promissora para a ocorrência de urânio, que se posiciona no extremo nordeste da Anticlinal Abaíra-Jussiape (Fig. 2). O contexto geológico é semelhante ao verificado no Complexo Lagoa Real e descrito por 
Lobato (1985), Maruèjol (1989), Cruz (2004) e Chaves et al. (2007), ou seja, trata-se de granitoides milonitizados em zonas de cisalhamento neoproterozoicas que hospedam a mineralização uranífera.

Unidades litoestratigráficas $\mathrm{O}$ mapeamento geológico realizado na escala 1:25.000 (Fig. 3) permitiu individualizar tonalitos-granodioritos, álcali-feldspato granitos, sienitos-quartzo-sienitos e albititos milonitizados da Suíte Caraguataí e granitos a granitos miloníticos da Suíte Jussiape. À exceção dos tonalitos-granodioritos, migmatizados ou não, as demais litofácies refletem tectonofácies relacionadas com a presença das zonas de cisalhamentos no núcleo da Anticlinal Abaíra-Jussiape e que estão relacionadas com a evolução do Corredor do Paramirim. Em todas as tectonofácies foram encontradas microestruturas: (i) porfiroclástica, núcleo-manto e milonítica, exibidas

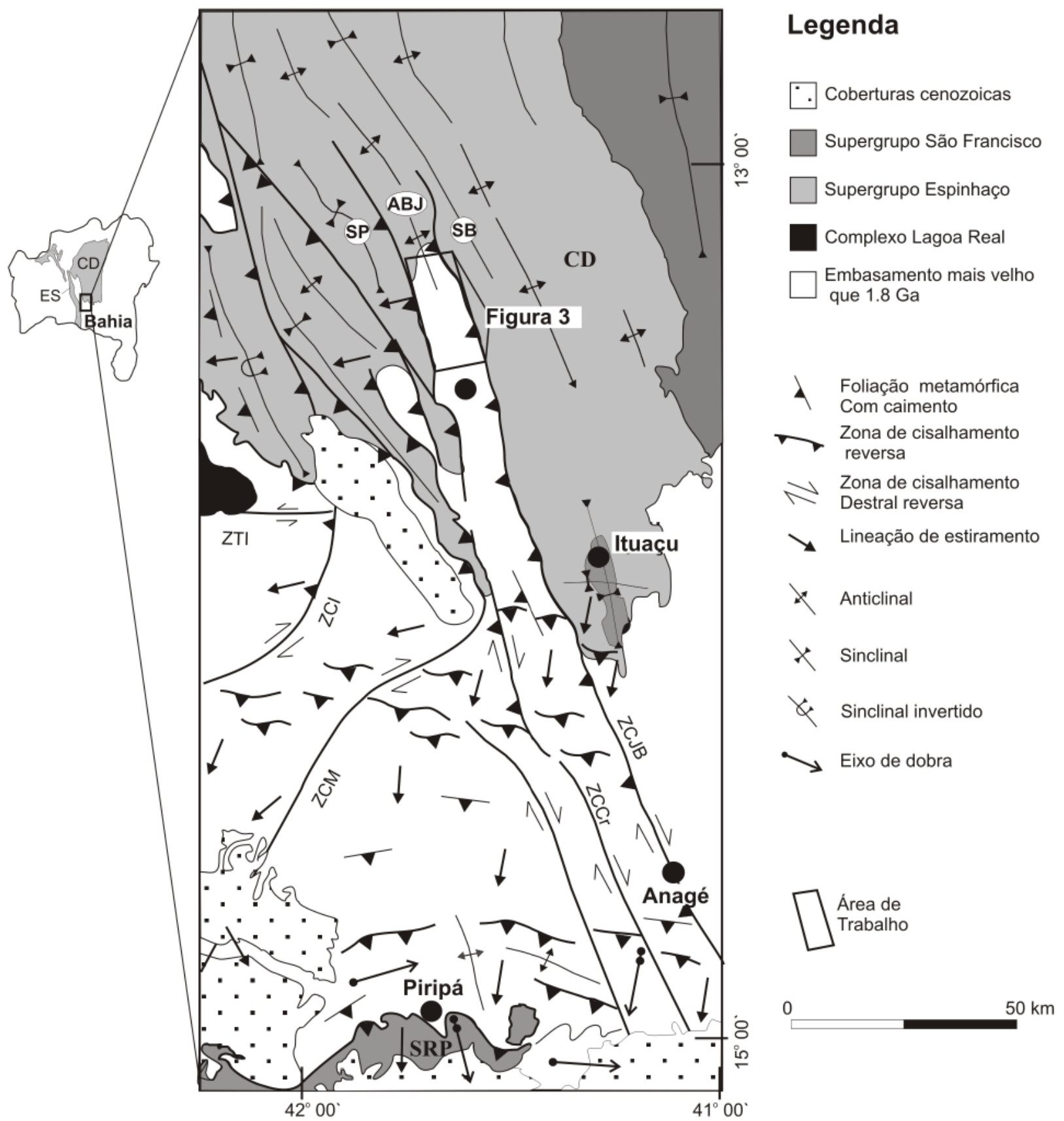

Figura 2 - Localização da Anticlinal Abaíra-Jussiape e da área selecionada para a modelagem metalogenética desse trabalho. A caixa indica o Anticlinal Abairra-Jussiape. Zonas de cisalhamento: ZCI - Iguatemi, ZCM - Malhada de Pedras, ZCCr - Cristalândia, ZCJB - João Correia-Barra do Mendes, ZCBC - Brumado-Caetité. ZTI - Zona de transferências de Itanajé. CD - Chapada Diamantina, SRP - Saliência do Rio Pardo. SP - Sinclinal de Piatã, $S B$ - Sinclinal de Boninal, SAJ - Sinclinal Abaira-Jussiape. Figura extraída de Cruz (2004), baseado em Schobbenhaus et al. (1981), Almeida (1977) e Barbosa \& Dominguez (1996). A posição da figura encontra-se na figura 1. 


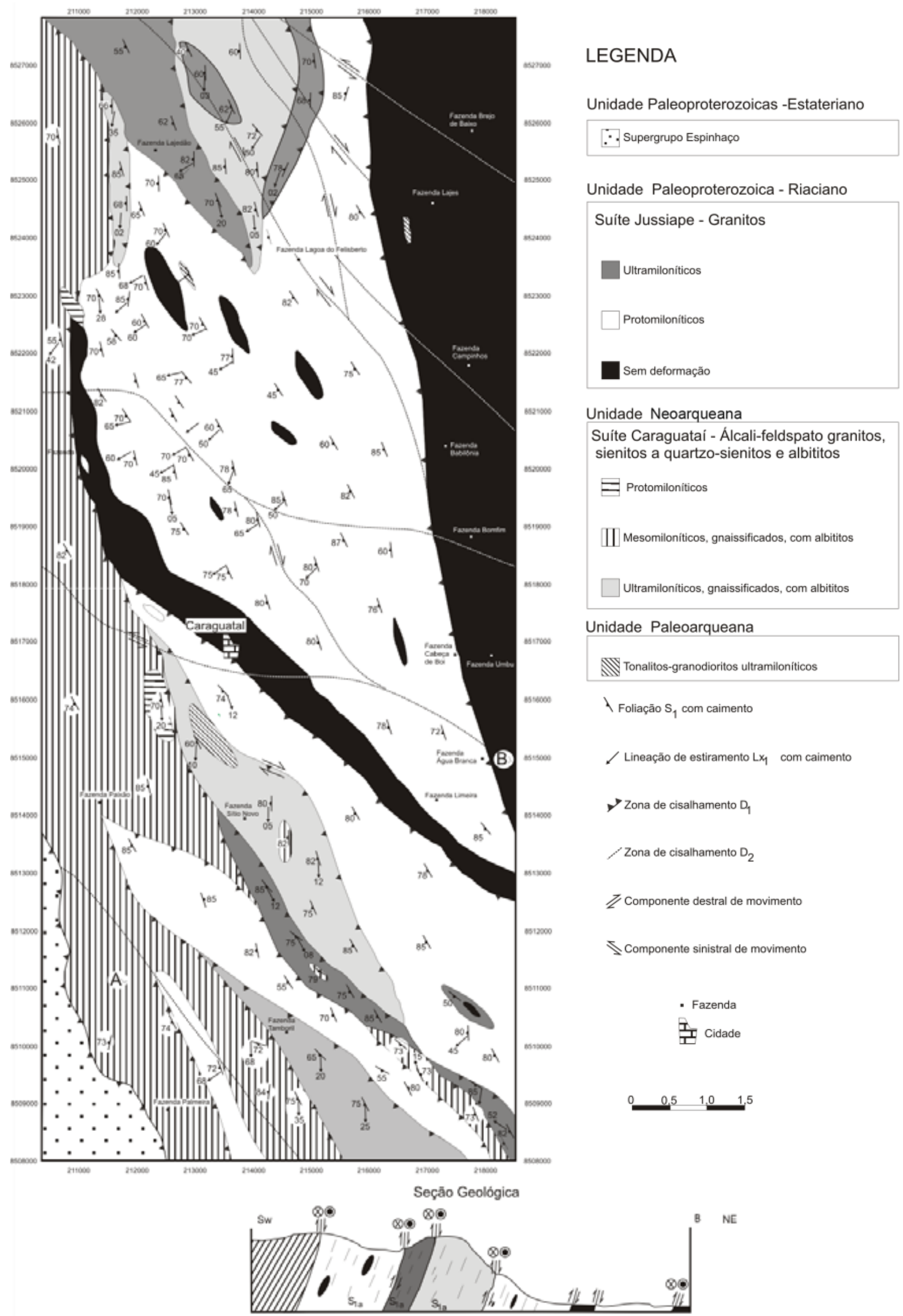

Figura 3 - Mapa Geológico da área de trabalho. 
pela presença de porfiroclastos de feldspatos e quartzo envolto por novos grãos recristalizados; (ii) granoblástica, representada pela presença de agregados granulares de feldspatos e quartzo; (iii) de reação metamórfica, pela presença de auréolas e pertitas em chamas em $\mathrm{K}$-feldspato; pelas microestruturas de equilíbrio entre plagioclásio, epidoto e mica branca (saussuritização); (iv) lepidoblástica, pela orientação preferencial de biotita; (v) pseudopoiquilítica, visível diante da inclusão de epidoto e mica branca em plagioclásio.

TONALITOS-GRANODIORITOS Essas rochas ocupam 3\% do total da área cartografada, não tendo sido verificada as suas relações de contato com as demais unidades (Fig. 3). Para Cruz (2004) e Guimarães et al. (2005), tratam-se de xenólitos que se encontram migmatizados, milonitizados e imersos nas rochas das suítes Caraguataí e Jussiape (Fig. 4a), descritas a seguir. Em alguns afloramentos, os gnaisses são cortados por injeções do Granito Jussiape. A composição modal dessas rochas é representada por plagioclásio (60-72\%), feldspato alcalino (5-12\%), quartzo (20-25\%), biotita $(0-6 \%)$, titanita $(1-3 \%)$, zircão $(<1 \%)$, magnetita $(1 \%)$, alanita $(0-1 \%)$, epidoto ( $2 \%$ ) e mica branca ( $1 \%)$. Nos domínios migmatizados podem ser encontradas estruturas estromáticas e nebulíticas.

\section{K-FELDSPATO GRANITOS, SIENITOS-QUARTZO-} -SIENITOS E ALBITITOS DA SUÍTE CARAGUATAÍ Essas unidades afloram a norte, a sul e na porção leste da área cartografada, correspondendo a $28 \%$ da área total. Nessa suíte foram identificadas tectonofácies protomilonítica, augen-mesomilonítica e ultramilonítica (Figs. 4b, c). No último caso, um proeminente bandamento gnáissico é observado. Em todas as tectonofácies identificadas observam-se veios de quartzo, de aplitos e de pegmatitos que estão, em geral, dobrados e paralelizados com a foliação principal das rochas e, na maioria das vezes, estirados. a)

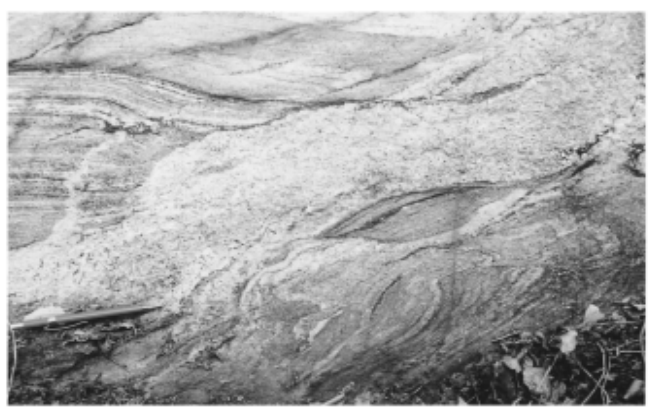

c)

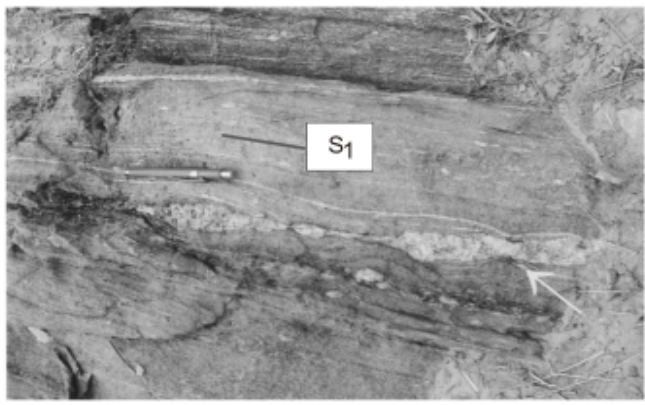

e)

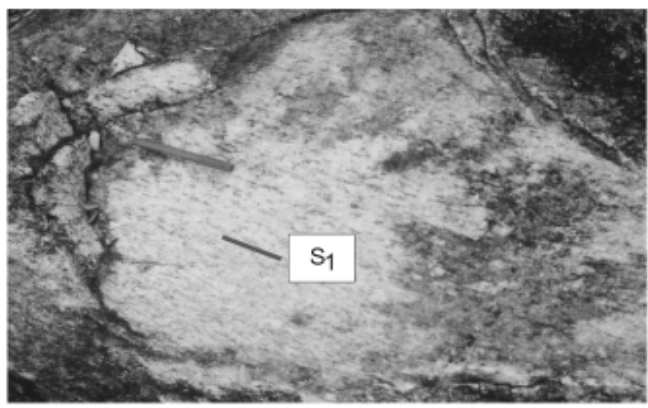

b)

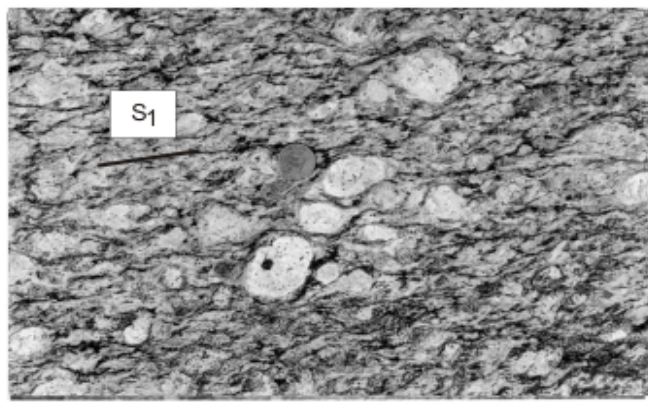

d)

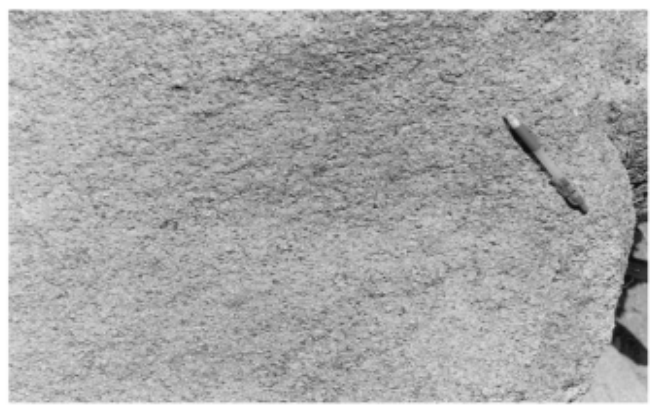

f)

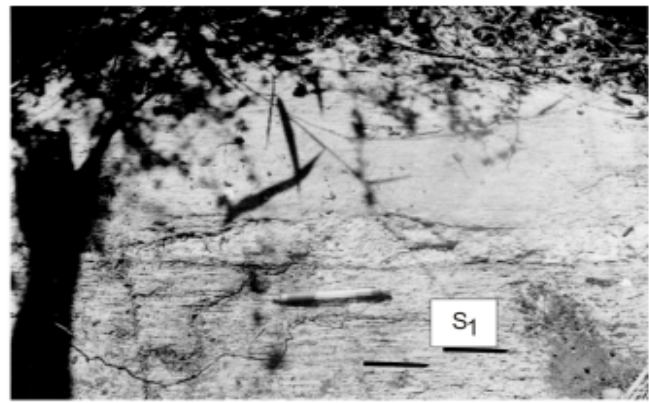

Figura 4 - Aspectos de campo dos tonalitos-granodioritos (a); K-feldspato granitos, sienitos a quartzo-sienitos mesomiloníticos (b) e ultramiloníticos (c) da Suite Caraguatai; granitos sem deformação (d), protomiloníticos (f) e ultramiloníticos (g) da Suite Jussiape. 
Nos sienitos e quartzo-sienitos protomiloníticos microestruturas primárias podem ser encontradas, estando representadas, sobretudo, pela presença de grãos subédricos, tabulares a colunares de feldspatos com grãos de quartzo ocupando os espaços entre eles. Mimerquitas podem também ser verificadas nessas rochas. A composição modal é representada por feldspato alcalino (70$85 \%)$, plagioclásio $(0-10 \%)$, quartzo $(2-25 \%)$, biotita castanha (5-12\%), magnetita/hematita (2-6\%), apatita $(1-2 \%)$, titanita (1-2\%), hastingsita/pargasita (1-2\%), zircão (1-3\%), mica branca (1-2\%), epidoto (0-2\%).

Os albititos foram encontrados nas imediações da localidade de Caraguataí, mas seus afloramentos são muito pouco expressivos. Em geral, formam corpos fusiformes, centimétricos a métricos, pouco espessos, paralelizados com a foliação milonítica. A principal microestrutura é a granoblástica, que raramente pode ocorrer sob a forma poligonal. A mineralogia dessas rochas é representada pela albita (70-90\%), biotita (0-5\%), hastingsita (2-8\%), magnetita (0-1\%) e hematita (0-2\%).

GRANITOS DA SUÍTE JUSSIAPE Essa unidade ocorre, preferencialmente, na região centro-leste, ocupando $70 \%$ da região cartografada. As tectonofácies identificadas constituem granitos sem deformação, granitos protomiloníticos e ultramiloníticos Jussiape (Figs. 4d e f).

A principal feição primária encontrada foi a foliação de fluxo magmático e a microestrutura traquítica, que estão ressaltadas pela orientação do feldspato alcalino. Nas rochas menos deformadas, o hábito colunar a tabular dos feldspatos é outra feição da rocha original. Em geral, as rochas dessa suíte apresentam-se pouco deformadas. Quando hospedam zonas de cisalhamento, desenvolvem um bandamento composicional gnáissico que, em geral, é raro.

Nas rochas investigadas foi encontrada a seguinte proporção modal: K-feldspato (40-75\%), quartzo (8$35 \%$ ), plagioclásio $(10-35 \%)$, biotita $(0-2 \%)$, titanita $(1-2 \%)$, magnetita $(1-2 \%)$, zircão $(1-3 \%)$, mica branca (0-2\%) e epidoto $(0-1 \%)$.

Os pegmatitos ocorrem intrusivos no Granito Jussiape e nos Gnaisses Caraguataí. Os corpos são tabulares e ocorrem ora alinhados com a foliação principal, ora ortogonais a ela. Não foi possível cartografar esses corpos devido à escala de trabalho. Geralmente, possuem granulação grossa, com cristais de quartzo e feldspato que variam entre 1 e $3 \mathrm{~cm}$. Os pegmatitos, em geral, são cortados por uma foliação milonítica espaçada marcada pela biotita que se posiciona preferencialmente nas bordas dos corpos. Na maioria das vezes, esses corpos apresentam variação granulométrica da borda (mais final) para o centro (mais grossa).

SUPERGRUPO ESPINHAÇO O Supergrupo Espinhaço está representado pela Formação Serra da Gameleira e pelo Grupo Rio dos Remédios (Guimarães et al. 2005, 2008). De acordo com aqueles autores, a Formação Serra da Gameleira é formada por quartzo-arenitos bimodais, brechas, grauvacas, arcóseos, conglomerados polimícticos e, subordinadamente, argilitos. Essas litofácies terrígenas teriam sido acumuladas em ambiente desértico, através de processos eminentemente eólicos. O Grupo Rio dos Remédios ocorre em discordância com angular e erosiva com as unidades da Formação Serra da Gameleira, descrita anteriormente, sendo subdividida, da base para o topo, nas formações Novo Horizonte, Lagoa de Dentro e Ouricuri do Ouro. Na zona periclinal da Anticlinal Abaíra-Jussiape afloram as unidades terrígenas da Formação Ouricuri do Ouro, que compreende metaquartzoarenitos com estratificações cruzadas acanaladas de grande porte, metarenito bimodal e conglomerados polimícticos, que foram depositados por sistema eólico/aluvial (Guimarães et al. 2005, 2008).

Em geral, as rochas terrígenas encontram-se bastante deformadas, como uma foliação desenvolvida paralelamente ao acamamento deposicional sedimentar.

Arcabouço estrutural $O$ levantamento estrutural permitiu a identificação de duas famílias de estruturas, uma compressional $\left(\mathrm{D}_{1}, \mathrm{D}_{2}\right)$, mais antiga, predominante, e outra distensional $\left(\mathrm{D}_{3}\right)$, a mais jovem, que aproveitou as estruturas anteriormente nucleadas.

FAMÍLIA COMPRESSIONAL Nesse contexto, foram reconhecidos dois conjuntos principais, aqui denominados de $\mathrm{D}_{1}$ e $\mathrm{D}_{2}$. Ambas estão associadas com zonas de cisalhamentos, entretanto a primeira com movimentos oblíquos a transcorrentes e a segunda com movimentos frontais.

As estruturas pertencentes à família compressional $\mathrm{D}_{1}$ são as que predominam na área cartografada, tendo sido responsáveis pelas deformações nas suítes Caraguataí e Jussiape e por demarcar os contatos tectônicos tal qual estão atualmente expostos. Elas constituem zonas de cisalhamento dúcteis, que desenvolvem bandamento composicional gnáissico, foliação milonítica $\left(\mathrm{S}_{1}\right)$ (Fig. 5a) com orientação preferencial em 245/81 (Fig. $5 b)$ e lineação de estiramento mineral $\left(\mathrm{Lx}_{1}\right)$ com orientação geral 236/52. Nesse caso, observa-se uma ampla dispersão da lineação de estiramento, desde alta até baixa obliquidade. Na figura 3, verifica-se que a sul da área estudada predomina a lineação de média a baixa obliquidade e a norte, progressivamente, ela vai se tornando de alta obliquidade. A foliação milonítica, entretanto, permanece posicionada preferencialmente segundo NW-SE. Além dessas estruturas, boudins e dobras intrafoliais foram também encontradas associadas com $\mathrm{D}_{1}$. Indicadores cinemáticos observados no plano $\mathrm{XZ}$, tais como estruturas $\mathrm{S} / \mathrm{C}$ e dobras assimétricas, sugerem movimentos destral-reversos a destrais para zonas de cisalhamento nucleadas nessa fase. Nos tectonitos sin- $\mathrm{D}_{1}$, feições de deformação dúctil (dislocation creep) (extinção ondulante, formação de subgrãos) nos feldspatos são amplamente observadas. Também nessas rochas o mecanismo de recristalização por rotação de subgrãos é eficiente na geração da trama milonítica. A temperatura mínima de deformação é marcada pelos feldspatos, que, em condições inferiores a $550^{\circ} \mathrm{C}$ deforma-se ruptilmente e não se recristaliza (Voll 1976, Tullis 1983, Simpson 1985, 1986, Vauchez 1987, Stipp et al. 2002). 


\section{Anticlinal Abaíra-Jussiape Foliação $S_{1}$ \\ Máximo: 065/09 \\ Plano máximo: $245 / 81$}

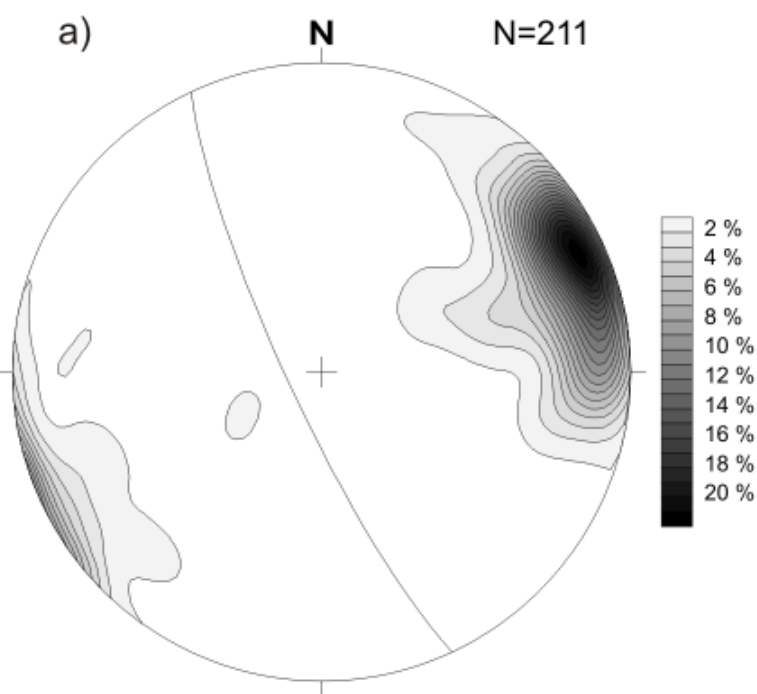

\section{Anticlinal Abaíra-Jussiape \\ Lineação de estiramento $L x_{1}$ \\ Máximo: 236/52}

b)

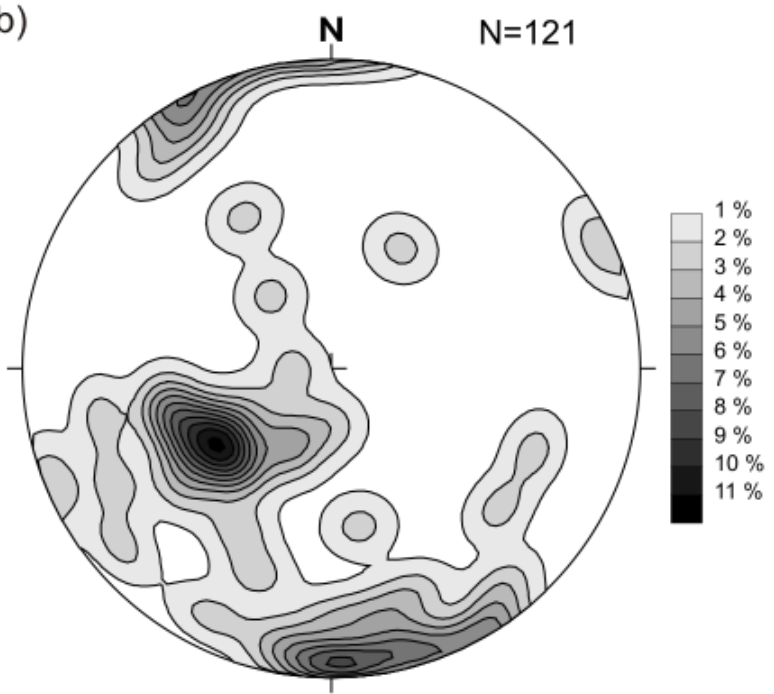

Figura 5 - Diagramas estereográficos sinópticos das estruturas deformacionais da fase $D_{r}$. Hemisfério inferior, $N=$ número de medidas.

A partir dos elementos estruturais levantados, foram reconhecidos dois domínios estruturais, denominados de I e II (Fig. 6), relativos à fase de deformação $\mathrm{D}_{1}$. O Domínio I possui baixa deformação, com feições magmáticas ainda preservadas e corresponde à área de ocorrência do granito Jussiape. O Domínio II, por sua vez, é marcado por zonas de cisalhamento dúcteis da fase $\mathrm{D}_{1}$ e corresponde á área de ocorrência da Suíte Caraguataí.

As estruturas da fase $\mathrm{D}_{2}$ ocorrem truncando todas as rochas cartografadas e estão representadas por estreitas zonas de cisalhamento de natureza dúctil-rúptil, que desenvolvem dobras de arrasto sobre a $S_{1}$, foliação milonítica $\mathrm{S}_{2}$ e fraturas de tração ocupadas por veios de quartzo e de magnetita. Suas zonas de cisalhamento apresentam orientação preferencial $270 / 80$ e lineação de estiramento em 253/78 (Figs. 7a e 7b). São zonas de alto ângulo, em que a cinemática varia entre reversa-destral a reversa-sinistral, em função da posição dessas zonas em relação à tensão principal regional. A foliação $\mathrm{S}_{2}$ é mais bem desenvolvida na microescala, sendo marcada por mica branca, clorita e quartzo. Com base nas feições verificadas em lâmina, especialmente em função dos processos de fragmentação de feldspatos e dissolução do quartzo, sugere-se que a temperatura de deformação deve ter sido inferior a $550^{\circ} \mathrm{C}$ (Voll 1976, Tullis 1983, Simpson 1985, 1986, Vauchez 1987, Stipp et al. 2002). Por sua vez, a presença do quartzo recristalizado sugere temperaturas de deformação acima dos $300^{\circ} \mathrm{C}$ (Voll 1976, Tullis 1983).

FAMÍLIA DISTENSIONAL Essa família, que está relacionada com a fase $\mathrm{D}_{3}$, é representada por zonas de cisalhamento normais que se sobrepõem às estruturas de cisalhamento anteriormente descritas. Importantes indicadores de movimento normais foram observados em campo, tais como dobras de arrasto e estruturas S/C. Em geral, os movimentos são frontais com a lineação de estiramento posicionando-se em alta obliquidade.

Alteração hidrotermal $\mathrm{Na}$ área modelada, a análise petrográfica e microestrutural revelou a presença de feições ameboides a esqueletiformes e feições em chamas de albita $(\mathrm{Ab}=100 \%, \mathrm{An}=0 \%)$ em feldspato alcalino quando ocorrem como porfiroclastos subédricos a anédricos. Essas feições representam processos de alteração hidrotermal por albitização. As zonas de alteração aparecem tanto nos granitoides e sienitoides menos deformados, quanto nos domínios de maior deformação, representados pelos termos gnaissificados. Neste caso, as frentes de albitização apresentam-se paralelizadas com a foliação principal. Aspecto relevante é que os domínios albitizados são truncados por feições de recristalização sin-tectônica à principal fase deformacional da área. Tal feição sugere que a albitização é anterior à deformação verificada nas rochas do núcleo da anticlinal Abaíra-Jussiape, como também foi observado por Cruz (2004) nas encaixantes da mineralização uranífera do Complexo Lagoa Real. Além disso, domínios de potassificação foram observados nas rochas da Suíte Jussiape, sendo que eles se encontram paralelizados com a foliação $S_{1}$.

Outro aspecto relevante que deve ser considerado é a presença da hematita, que se posiciona paralelamente à foliação milonítica sin- $\mathrm{D}_{1}$. Esse mineral foi encontrado apenas nas unidades da Suíte Caraguataí e Jussiape substituindo a magnetita e sugere a existência 


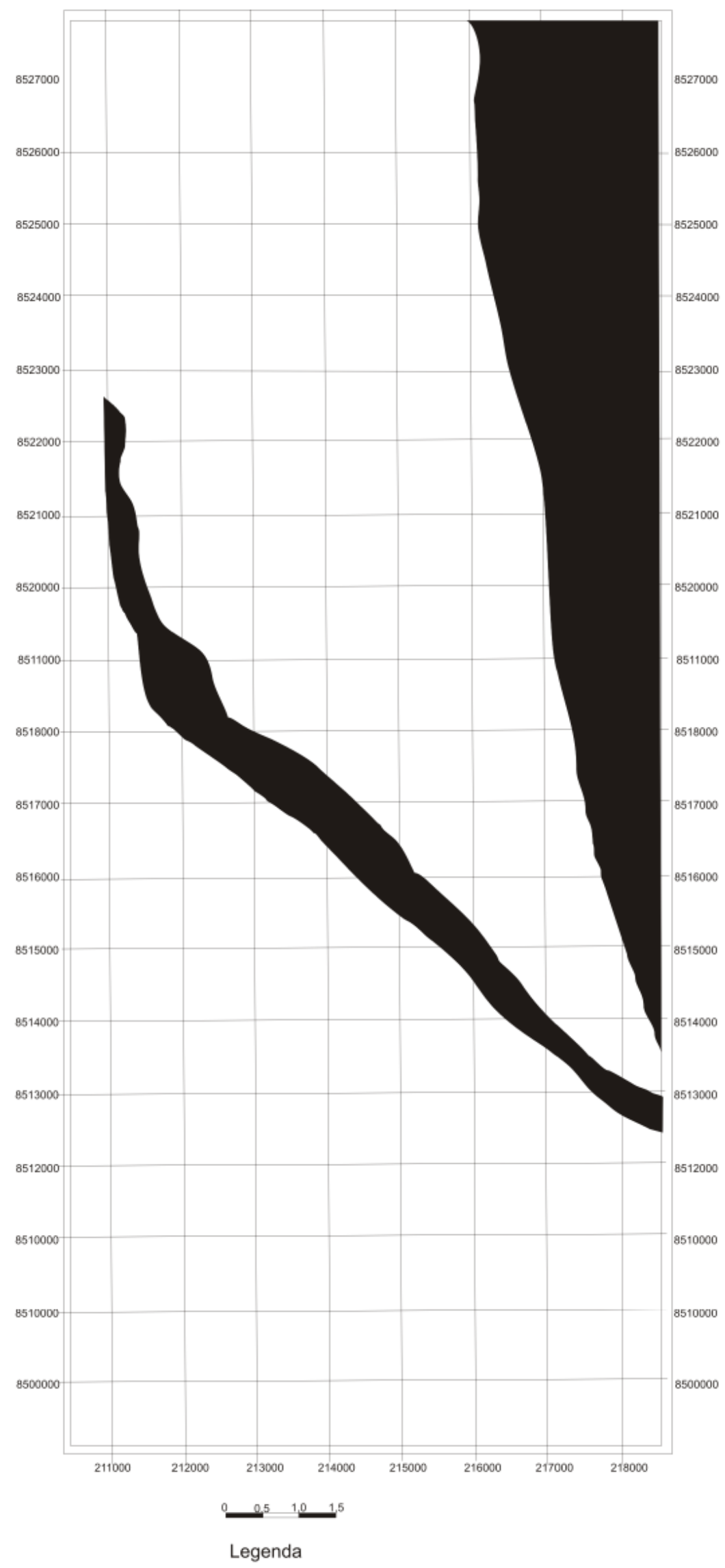

Domínio I - Baixa intensidade de deformação sin- $D_{1}$ com estruturas ígneas primárias preservadas

Domínio II - Média a alta intensidade de deformação sin- $D_{1}$; presença de meso e ultramilonitos

Figura 6 - Domínios estruturais relativos à fase $D_{1}$ no núcleo da Anticlinal Abaíra-Jussiape. 


\section{Anticlinal Abaíra-Jussiape \\ Foliação $\mathrm{S}_{2}$ \\ Máximo: 080/10 \\ Plano máximo: 270/80}

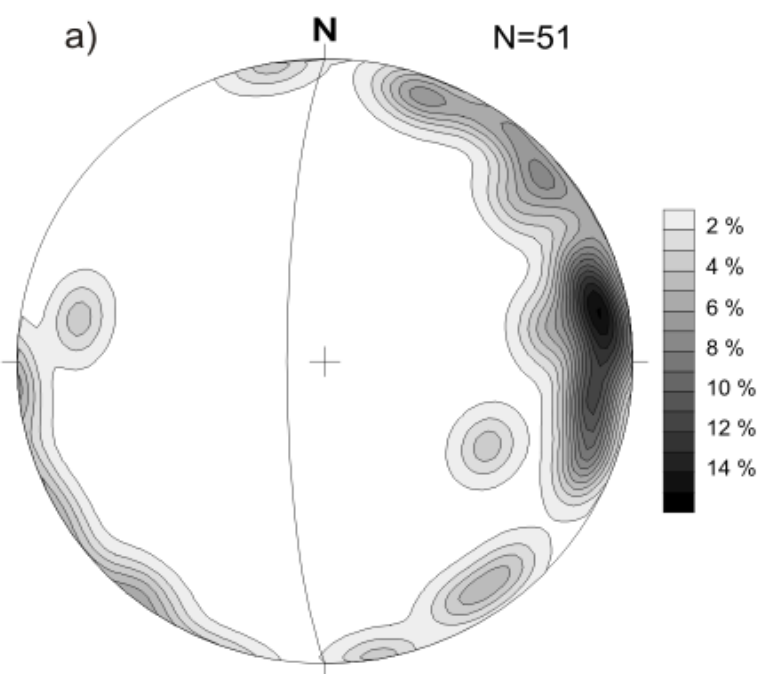

Anticlinal Abaíra-Jussiape

Lineação de estiramento Lx2

Máximo: 253/78

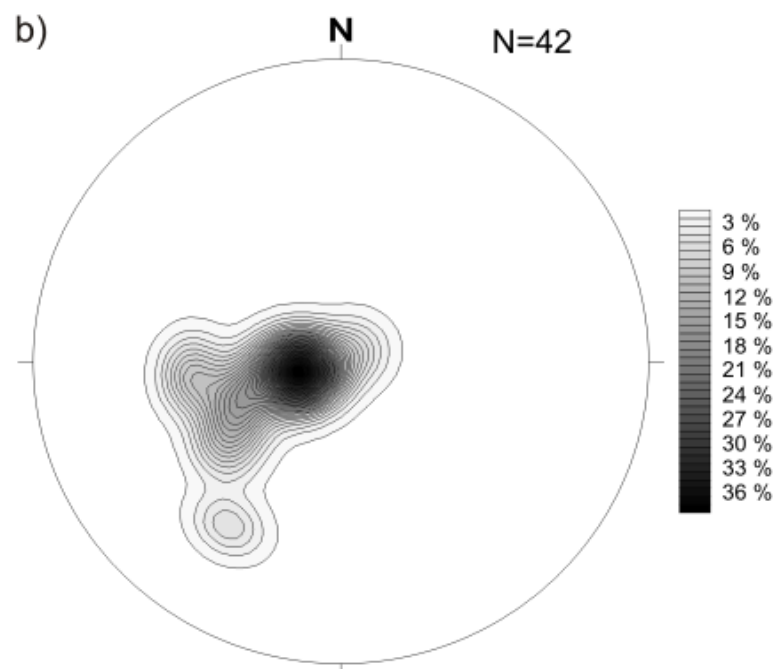

Figura 7 - Diagramas estereográficos sinópticos das estruturas deformacionais da fase $D_{1 b}$. Hemisfério inferior, $N=$ número de medidas.

de frentes de oxidação nessas rochas relacionadas com a principal fase de deformação identificada.

Associadas com a fase deformacional D2 foram encontradas feições que sugerem alteração hidrotermal (processos de silicificação, hidratação e saussuritização).

\section{MODELAGEM METALOGENÉTICA PARA} URÂNIO O uso do Sistema de Informações Geográficas (SIG) e do Processamento Digital de Imagens nas Geociências tem permitido a espacialização e integração de dados. $\mathrm{O}$ uso desse ferramental vem crescendo na pesquisa mineral, podendo ser citados os trabalhos de Bonham-Carter (1994), no Canadá; Perrotta (1996), Franca-Rocha (2001), Baars et al. (2003) e Guimarães et al. (2005), no Brasil.

O presente trabalho seguiu a mesma metodologia adotada por Guimarães et al. (2005). Esses autores utilizaram a lógica Fuzzy como método de modelagem espacial para cruzamento dos temas elaborados na escala 1:25.000, tais como litologia favorável, gamaespectometria terrestre e aerogamaespectometria (razões U/Th, $\mathrm{U} / \mathrm{K}$ e U total), densidade de estruturas, paragêneses de alteração hidrotermal, incluindo a hematitização e albitização com vistas a selecionar áreas favoráveis à pesquisa de urânio no núcleo da Anticlinal Abaíra-Jussiape.

A modelagem metalogenética foi realizada à luz da mineralização de urânio do Complexo Lagoa Real, tendo sido considerado que as zonas de albitização presentes em domínios mesomiloníticos a ultramiloníticos das zonas de cisalhamento sin- $\mathrm{D}_{1}$ seriam os sítios de maior favorabilidade para aquele elemento.

Os dados coletados em campo foram previamente organizados em tabelas, espacializados e, a seguir, transformados em grid para que pudessem ser processados. A seguir será apresentada a metodologia de trabalho e os resultados obtidos.

Aquisição, tratamento estatístico e processamento dos dados de cintilometria terrestre Durante os trabalhos de campo foram obtidos dados radiométricos terrestres de contagem total através do cintilômetro. Os dados da cintilometria terrestre foram organizados em planilha Excel e espacializados no software Arc Gis 8.3. Os parâmetros estatísticos desses dados como média, desvio padrão, assimetria, dentre outros, foram obtidos automaticamente através do programa Excel, que possui a extensão para análise de dados, a qual, disponibiliza a função estatística descritiva. As tabelas 1 e 2 apresentam os parâmetros estatísticos calculados e os valores das anomalias de primeira e segunda ordem, assim como o valor do background para os elementos radiativos da área selecionada para pesquisa. Esses valores, apesar de não discriminativos para urânio, servem como uma primeira análise para o levantamento das áreas com potencial para esse elemento.

Através da extensão Geostatistic Analyses do Arc Gis 8.3 foram confeccionadas as curvas de isoteores utilizando Krigagem como método de interpolação dos dados. Para essa interpolação foram testados outros métodos, e em todos os outros, o resultado obtido foi um grid com formas geométricas que não são correlacionáveis com a estruturação geológica da área. Estas curvas são arquivos do tipo shape que foram convertidas em grid para que pudessem ser aplicadas na modelagem (Fig. 8).

$\mathrm{Na}$ tabela 3 estão apresentados os pesos que foram atribuídos às classes dos dados de cintilometria. A classe selecionada para processamento com peso maior 
Tabela 1 - Parâmetros estatísticos obtidos a partir do tratamento de dados de cintilometria no software Excel.

\begin{tabular}{lc}
\hline Parâmetros estatísticos & Resultados obtidos \\
\hline \multicolumn{2}{l}{ Valores transformados para Log de base 10} \\
\hline Média & 2,570847 \\
\hline Erro padrão & 0,011954 \\
\hline Mediana & 2,579784 \\
\hline Moda & 2,69897 \\
\hline Desvio padrão & 0,226816 \\
\hline Variância da amostra & 0,051445 \\
\hline Curtose & 1,626734 \\
\hline Assimetria & 0,290662 \\
\hline Intervalo & 2 \\
\hline Mínimo & 1,69897 \\
\hline Máximo & 3,69897 \\
\hline Soma & 925,5048 \\
\hline Contagem & 360 \\
\hline Nível de confiança $(95,0 \%)$ & 0,023509 \\
\hline
\end{tabular}

Tabela 2 - Valores de anomalias encontrados a partir dos dados transformados para log de base 10.

\begin{tabular}{lcc}
\hline $\begin{array}{l}\text { Definição das anomalias } \\
\text { para os dados em CPS }\end{array}$ & $\begin{array}{c}\text { Valor da } \\
\text { anomalia em log } \\
\text { de base 10 }(\mathrm{cps})\end{array}$ & $\begin{array}{c}\text { Valores } \\
\text { convertidos para } \\
\text { Ant log }(\mathrm{cps})\end{array}$ \\
\hline $1^{\mathrm{a}}$ ordem & 3,251295 & 1783,6 \\
\hline $2^{\mathrm{a}}$ ordem & 3,024479 & 1057,9 \\
\hline $3^{\text {a } \text { ordem }=\text { Background }}$ & 2,797663 & 627,6 \\
\hline
\end{tabular}

na modelagem é a que corresponde ao intervalo entre 1783,6 e $5000 \mathrm{cps}$, ou seja, o intervalo correspondente às anomalias de primeira ordem (Fig. 8).

Aquisição dos dados aerogeofísicos Os grids dos temas da aerogeofísica foram elaborados a partir do recorte para os limites da área de estudo das imagens da geofísica, já processadas anteriormente por Guimarães et al. (2005). Essas imagens foram recortadas no software Oásis Montaj da Geosoft e reclassificadas para que pudessem ser processadas (Figs. 9 a 11). No grid do urânio foram determinadas quatro classes (Fig. 9), tendo sido atribuído o maior peso para valores acima de $15 \mathrm{ppm}$, este é o teor apresentado para os dados que estão acima do limiar de 97,5\%. Para o grid do U/K (Fig. 10) foram consideradas apenas duas classes: uma para valores maiores do que 6 (acima do limiar de 97,5\% dos dados), com peso maior, e outra com valores menores do que 6, com peso menor. Para o grid do U/Th
Tabela 3 - Fuzzyficação dos temas para urânio baseado nomodelo da mineralização de urânio do Complexo Lagoa Real.

\begin{tabular}{|c|c|}
\hline Tema & $\begin{array}{c}\text { Membro } \\
\text { Fuzzy }\end{array}$ \\
\hline \multicolumn{2}{|l|}{ Geofísica aérea } \\
\hline \multicolumn{2}{|l|}{ Urânio } \\
\hline$>20 \mathrm{ppm}$ & 0,9 \\
\hline $20-15 \mathrm{ppm}$ & 0,8 \\
\hline $15-10 \mathrm{ppm}$ & 0,7 \\
\hline $10-5 \mathrm{ppm}$ & 0,1 \\
\hline $0-5 \mathrm{ppm}$ & 0,0 \\
\hline \multicolumn{2}{|l|}{$\mathrm{U} / \mathrm{Th}$} \\
\hline$>3$ & 0,8 \\
\hline $2-3$ & 0,5 \\
\hline $1-2$ & 0,2 \\
\hline $0-1$ & 0,1 \\
\hline \multicolumn{2}{|l|}{$\mathrm{U} / \mathrm{K}$} \\
\hline$<=6$ & 0,1 \\
\hline$>6$ & 0,8 \\
\hline \multicolumn{2}{|l|}{ Geofisica terrestre (cintilometria) } \\
\hline$<627,6 \mathrm{cps}$ & 0,2 \\
\hline $627,6-1057,9$ & 0,7 \\
\hline $1057,9-1783,6$ & 0,8 \\
\hline $1783,6-5000$ & 0,9 \\
\hline \multicolumn{2}{|l|}{ Litologia Favorável } \\
\hline Ultramilonitos Caraguataí & 0,7 \\
\hline Ultramilonito Jussiape & 0,7 \\
\hline Milonito Caraguataí & 0,6 \\
\hline Granito Jussiape sem deformação & 0,2 \\
\hline Ultramilonitos tonalíticos-granodioríticos & 0,1 \\
\hline Protomilonitos Caraguataí & 0,1 \\
\hline Protomilonito Jussiape & 0,1 \\
\hline Supergrupo Espinhaço & 0,1 \\
\hline \multicolumn{2}{|c|}{ Lineamentos estruturais + Zonas de cisalhamento dúcteis } \\
\hline Área onde foram mapeados & 0,7 \\
\hline Área onde não foram mapeados & 0,2 \\
\hline \multicolumn{2}{|l|}{ Alteração hidrotermal (Albitização e Oxidação) } \\
\hline Zonas com a presença de alteração hidrotermal & 0,7 \\
\hline Zonas sem a presença de alteração hidrotermal & 0,2 \\
\hline
\end{tabular}

(Fig. 11), adotou-se uma postura mais permissiva, tendo sido obtidas quatro classes e atribuído o peso maior para a classe cuja razão estava acima de $0,0115 \mathrm{ppm}$, teor apresentado para os dados que estão acima do limiar de $50 \%$. 


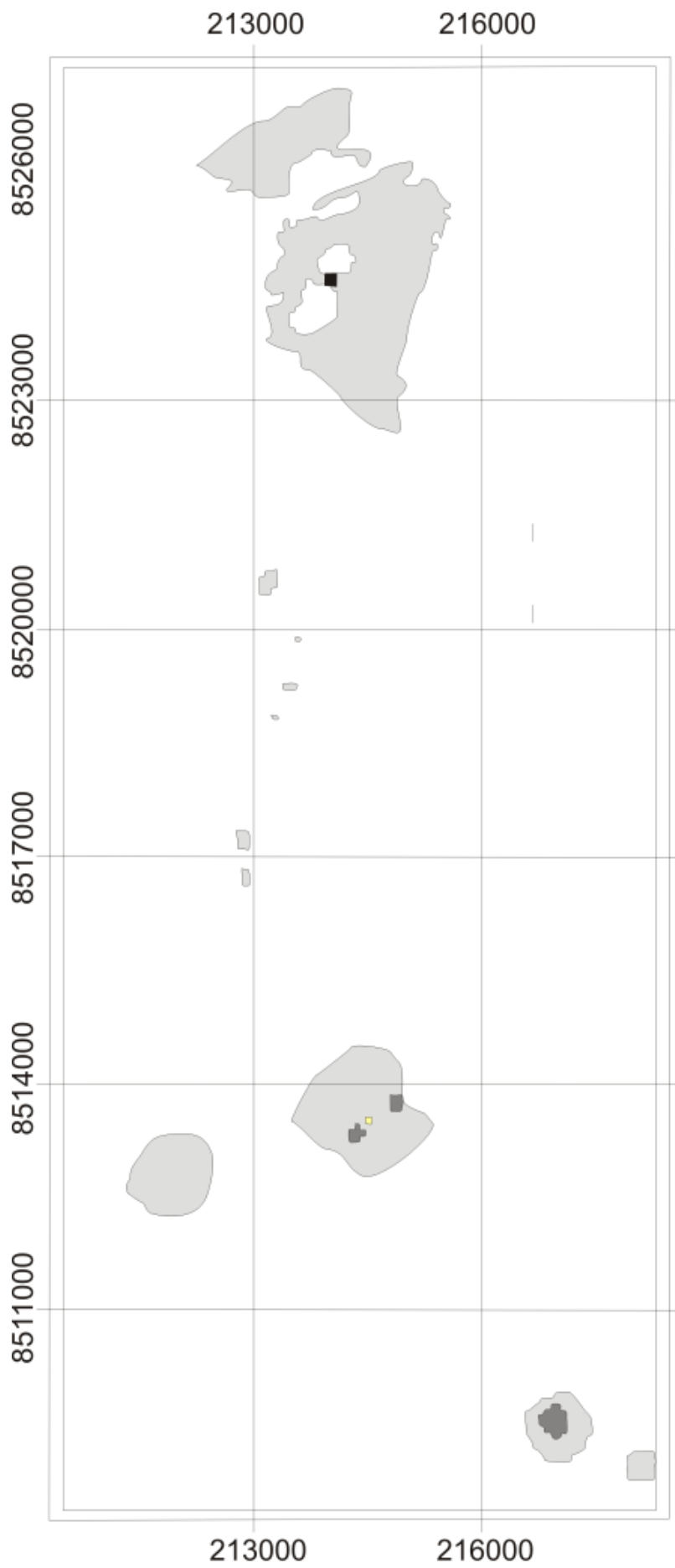

Grid com as áreas das anomalias (CPS)
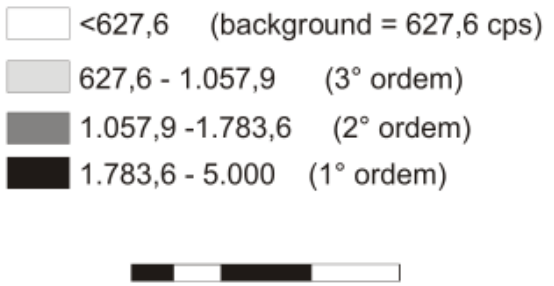

Figura 8 - Grid com as anomalias de primeira, segunda e terceira ordens (vide Tab. 1) gerado pelo método de Krigagem no software Arc Gis 8.3.

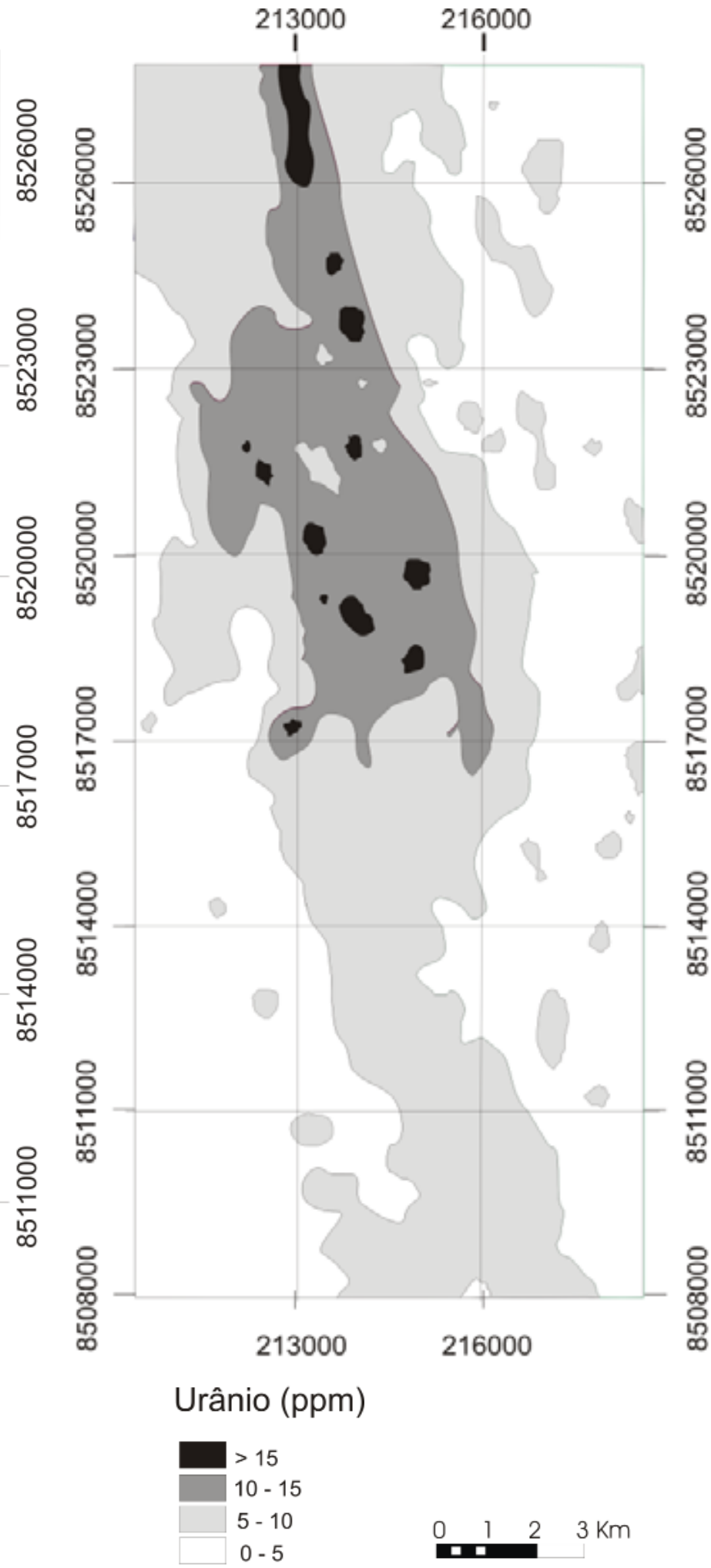

Figura 9 - Grid do canal do urânio.

Processamento dos dados das litologias $O$ levantamento geológico permitiu identificar litofácies da Suíte Caraguataí e da Suíte Jussiape, que foram milonitizadas e gnaissificadas em zonas de cisalhamentos sin$-\mathrm{D}_{1}$, relacionadas com a inversão do Aulacógeno do Paramirim, no Neoproterozoico. À luz dos controles 
litológicos e estruturais para a mineralização de urânio do Complexo Lagoa Real, em que a paragênese mineralizada é constituída preferencialmente por hematita e albita e está hospedada em rochas miloníticas, atribuiu-se pesos diferenciados, tanto para os domínios com indicações de alteração hidrotermal ligadas àquelas fases minerais, assim como para os domínios estruturais identificados. Neste sentido, considerou-se que os domínios prioritários para a pesquisa de urânio são os que apresentam alteração relacionada com a albitização e com a oxidação da magnetita-formação da hematita, assim como os domínios miloníticos relacionados

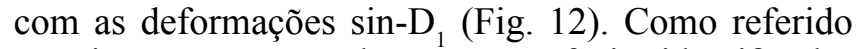
anteriormente, para todas as tectonofácies identificadas (Fig. 3) foram atribuídos pesos, conforme a tabela 3. As unidades para as quais foram atribuídos pesos maiores foram as que apresentaram uma maior intensidade de deformação dúctil, ou seja, as litofácies ultramiloníticas. Além disso, foram dados pesos superiores para os pontos com valores em cps acima do valor calculado para as anomalias de segunda ordem (vide Tab. 2).

Aquisição dos dados de lineamentos estruturais a partir de sensoriamento remoto Os lineamentos estruturais foram obtidos com o auxílio do software ENVI 3.4, que através do método de filtragem permitiu o realce das estruturas dúcteis, com orientação NW-SE (Fig. 13). Os lineamentos obtidos foram agrupados, tendo sido posteriormente gerado o Buffer com área de influência de $100 \mathrm{~m}$, uma vez que os temas a serem processados na modelagem devem ter o atributo de área e não de linha. A determinação do domínio de influência dos lineamentos estruturais foi feita com base na avaliação da sua distribuição na área estudada, levando-se em consideração a sua largura, sendo portanto, um parâmetro qualitativo. Este tema foi então convertido em grid para que pudesse ser processado na modelagem.

Foram atribuídos maiores pesos $(0,7)$ para os domínios onde foram extraídos dados de alinhamentos estruturais, juntamente com as zonas de cisalhamento dúcteis mapeadas (Tab. 3).

Integração dos dados obtidos: resultados e discussões da modelagem A confecção das diversas shapes e suas conversões em grids possibilitou o cruzamento dos dados de geologia e geofísica. A modelagem foi realizada a partir da utilização da Extensão ArcSdm no ArcView 3.3. A combinação entre os temas para o uso da metodologia de análise espacial foi realizada da seguinte forma:

a) combinação entre o tema da geologia e das estruturas (lineamentos e zonas de cisalhamento dúcteis) através do operador AND, resultando no tema Fator Geologia;

b) cruzamento entre os temas da geofísica aérea (Urânio, U/Th e U/K) através do operador AND, resultando no tema "Fator Geofísica";

c) combinação do resultado obtido no item " $b$ " com o tema das anomalias em cps, resultando no tema "Geofísica + cps";

d) cruzamento do resultado obtido no item "a" com o resultado obtido no item "c" através do operador AND,

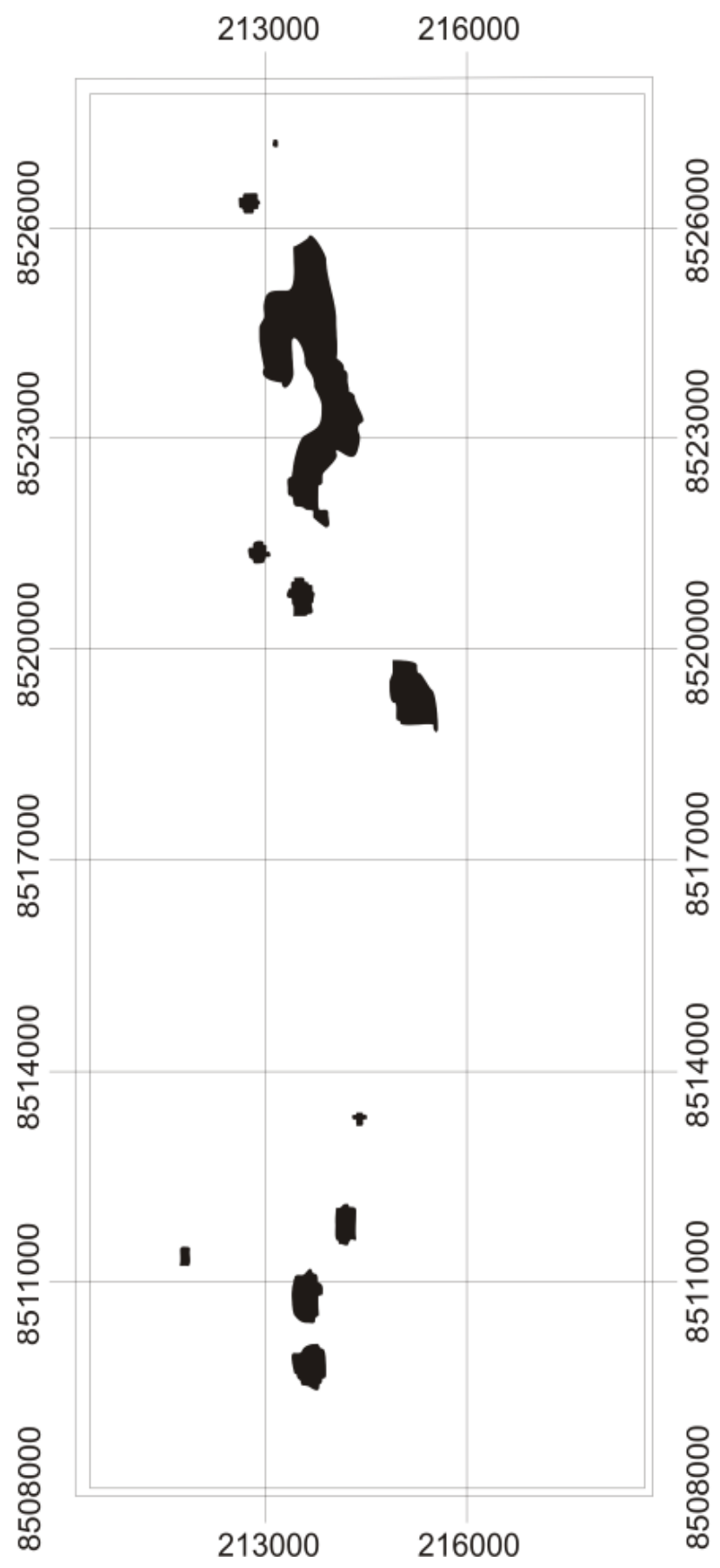

Razão U/K

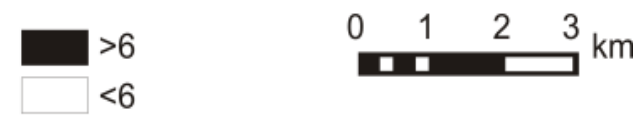

Figura 10 - Grid da razão U/K.

resultandono tema "FatorGeologia+Geofísica+cps"; e) cruzamento do resultado obtido no item "d" com o tema das pertitas metassomáticas através do operador GAMMA, resultando, no tema que corresponde às áreas com favorabilidade para urânio. 


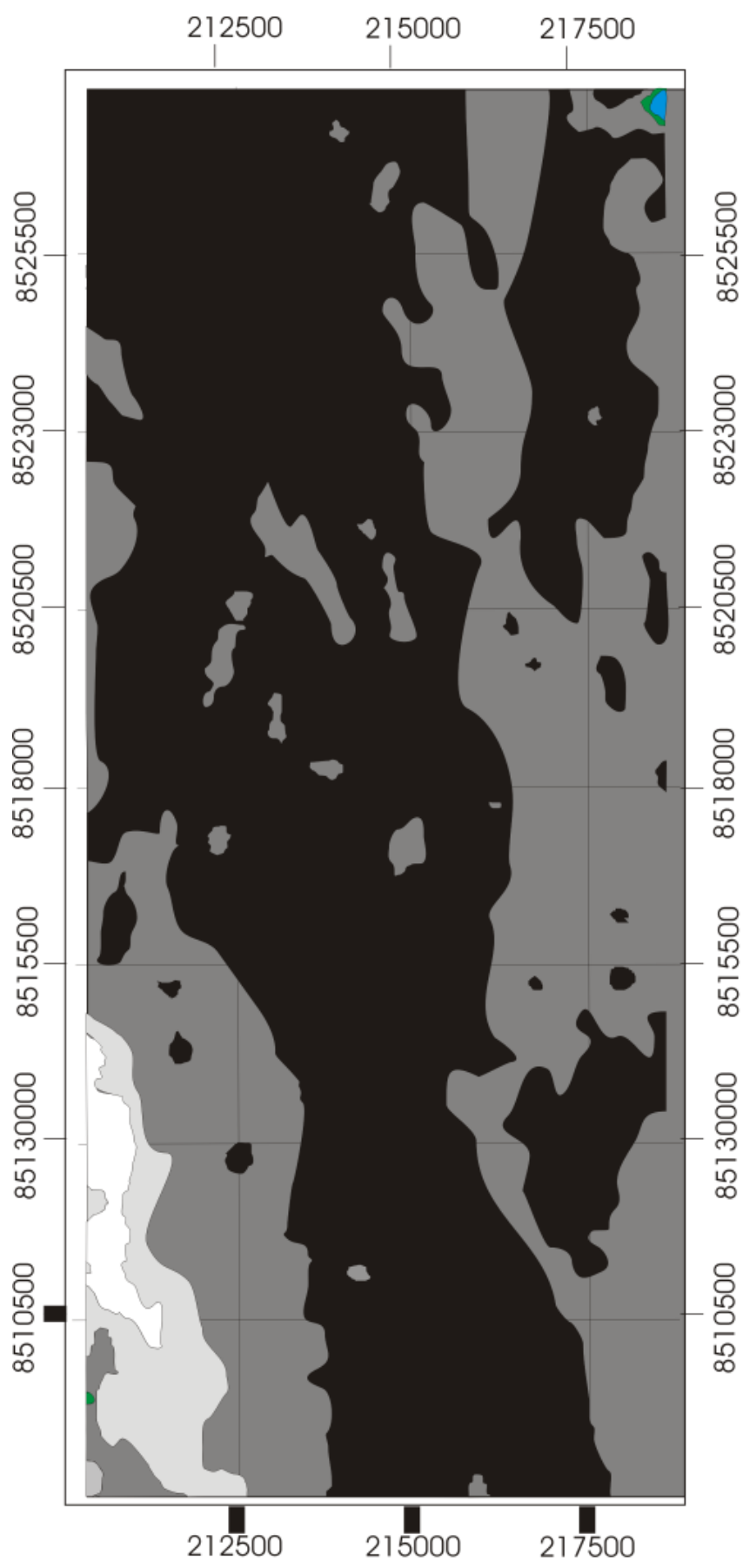

Razão U/Th

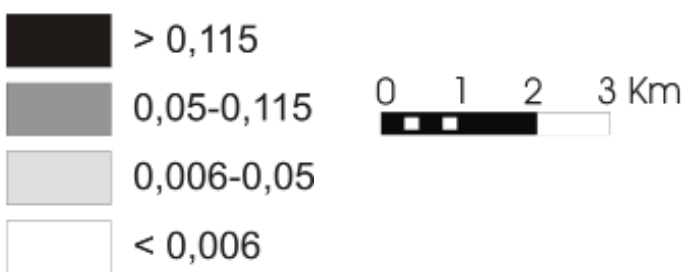

Figura 11 - Grid da razão U/Th.

A modelagem realizada permitiu identificar duas áreas com favorabilidade em urânio no núcleo da Anticlinal Abaíra-Jussiape (Fig. 14), que coincidem com os domínios onde foram obtidos os maiores valores em

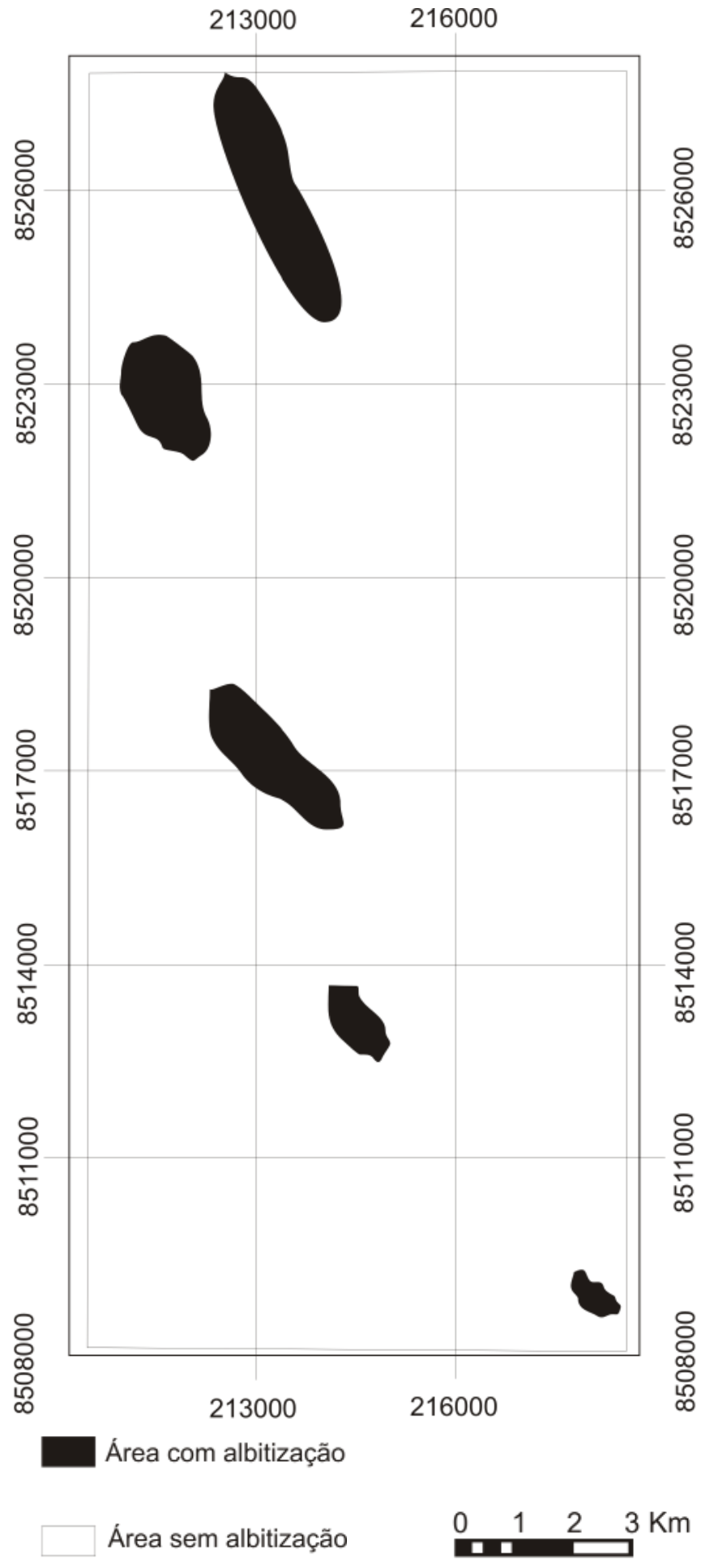

Figura 12 - Domínios coma presença de feições relacionadas com a albitização.

cps das medidas coletadas em campo com o cintilômetro (Fig. 8). Esses domínios têm como substrato as unidades meso a ultramiloníticas da Suíte Caraguataí e localizam-se na região a norte da área investigada, à aproximadamente $1000 \mathrm{~m}$ da Fazenda Lajedão, e na região a sul da área estudada, a cerca de $1500 \mathrm{~m}$ da Fazenda Sítio Novo. Nelas, os maiores valores de cintilometria encontrados estão, em sua maioria, abaixo do 
valor desejável para que se tornem anomalias de primeira ordem, ou seja, abaixo de 1.783,6 cps (vide Tab. 2). Entretanto, a similaridade do controle litológico e estrutural dessas anomalias com aquelas registradas no Complexo Lagoa Real, também no Corredor do Paramirim, fazem como que sejam locais potenciais para a pesquisa geológica de maior detalhe.

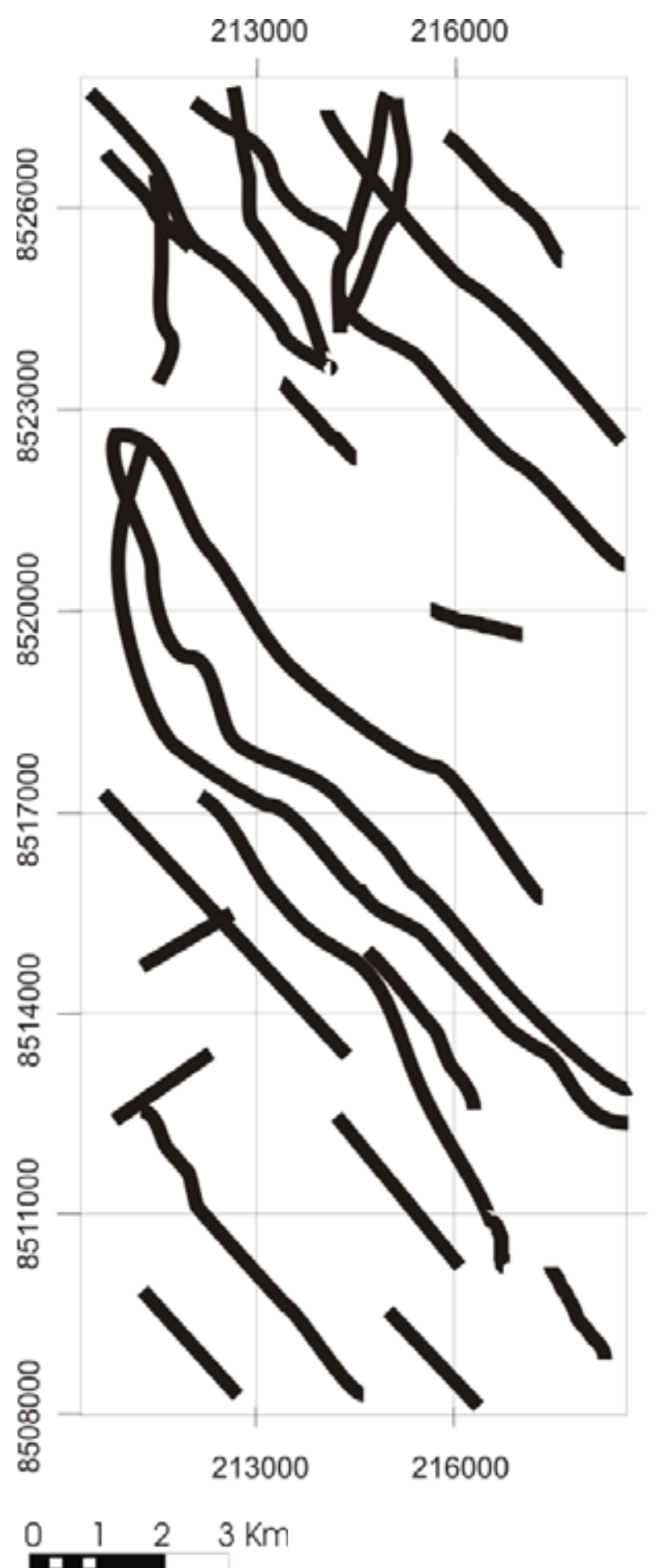

8
8
0
10
$\wp$

Figura 13 - Grid dos lineamentos extraídos da imagem de radar juntamente com as zonas de cisalhamento dúcteis da fase $D_{I}$.

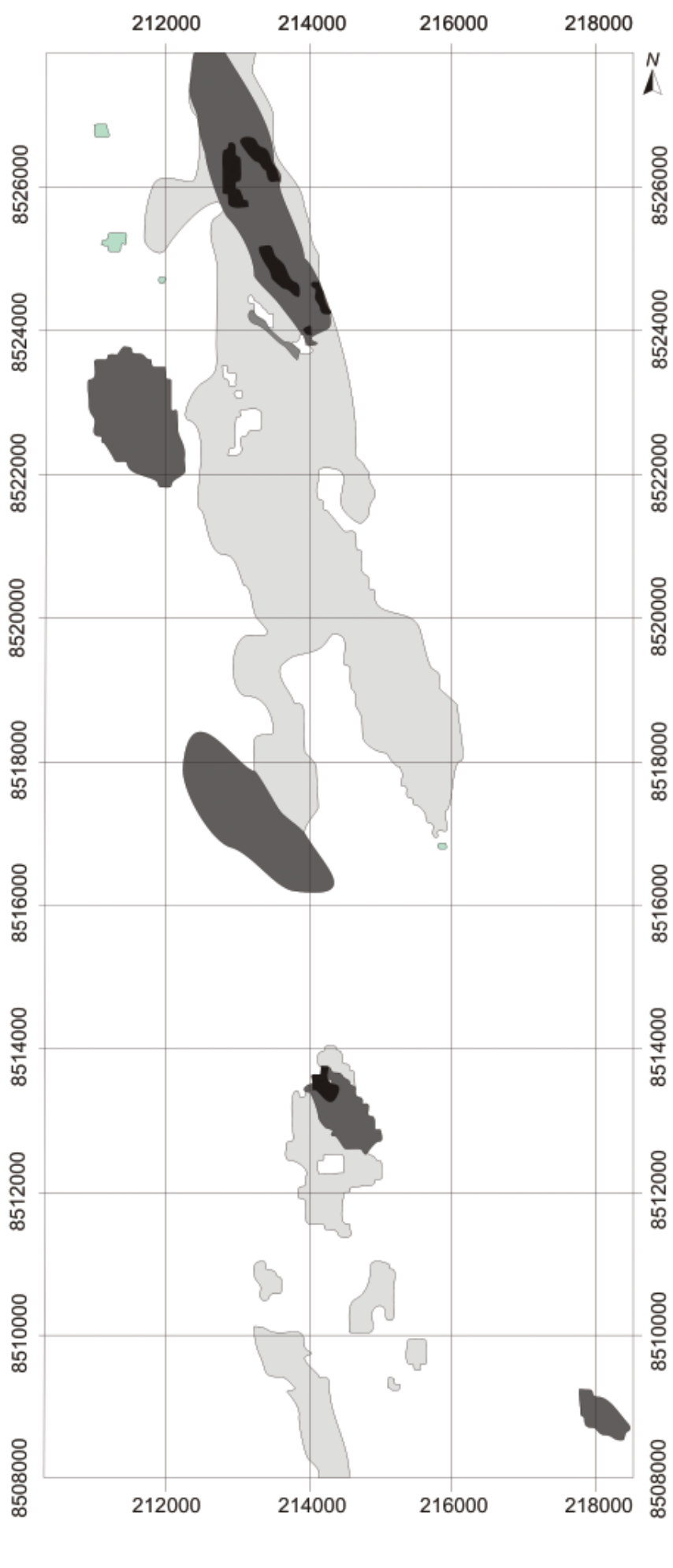

Possibilidade Fuzzy

$0.215-0.286$

0.286-0.5

$0.5-0.642$

$0.642-0.855$

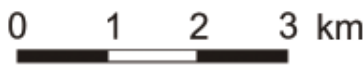

Figura 14 - Áreas com favorabilidade para mineralização de urânio no núcleo da Anticlinal Abaíra-Jussiape. 
CONCLUSÕES O levantamento geológico realizado no setor norte da Anticlinal Abaíra-Jussiape permitiu a identificação de rochas das suítes Caraguataí e Jussiape que foram milonitizadas e gnaissificadas em zonas de cisalhamento dúcteis reversa a reversa destral. Tais zonas de cisalhamento apresentam um historia evolutiva relacionada com a estruturação do Corredor do Paramirim, no Neoproterozoico, que foi subdividida nas fases $\mathrm{D}_{1}, \mathrm{D}_{2}$, compressionais, e $\mathrm{D}_{3}$, distensional. A principal fase de deformação identificada é a $\mathrm{D}_{1}$, que gnaissificou as rochas e estruturou os contatos entre as unidades. Os estudos petrográficos permitiram individuar três fases de alteração hidrotermal. A primeira, pré- $\mathrm{D}_{1}$, está relacionada com a potassificação e albitização da Suíte Caraguataí. A segunda, sin- $\mathrm{D}_{1}$, levou à oxidação da magnetita-formação da hematita. A terceira, sin- $\mathrm{D}_{2}$ e Sin- $\mathrm{D}_{3}$, está associada com a hidratação e saussuritização das rochas das suítes Caraguataí e Jussiape. A luz dos controles estruturais e litológicos do
Complexo Lagoa Real, a modelagem metalogenética realizada utilizando-se dados geológicos (identificação das litologias, petrologia, análise estrutural) e geofísicos (cintilometria terrestre e aerogamaespectometria) levou à identificação de duas áreas promissoras para a pesquisa de urânio, cujo significado geológico deverá ser mais bem pesquisado no futuro.

Agradecimentos Os autores querem expressar seus agradecimentos ao CNPq pela bolsa de Pós-Doutorado Júnior de Simone C.P. Cruz (Processo 150127/2005-7), assim como pelos recursos disponibilizados através do Edital Universal (Processo 475092/2004-0). Os autores agradecem também às Indústrias Nucleares do Brasil-INB, na pessoa do Dr. Evando Carele Matos, pela disponibilização do Cintilômetro. Por fim, agradecem à Companhia Baiana de Pesquisa Mineral-CBPM pelo apoio nas campanhas de campo.

\section{Referências}

Alkmim F.F., Brito Neves B.B., Alves J.A.C. 1993. Arcabouço tectônico do Cráton do São Francisco - uma revisão. In: Dominguez J.M. \& Misi A. (eds.) O Cráton do São Francisco. Reunião Preparatória do II Simpósio sobre o Cráton do São Francisco. Salvador, SBG/ Núcleo BA/SE/SGM/CNPq. p. 45-62.

Alkmim F.F., Pedrosa-Soares A.C., Noce C.M., Cruz S.C.P. 2007. Sobre a evolução tectônica do Orógeno AraçuaíCongo Ocidental. Geonomos, 1:25-43.

Almeida F.F. 1977. O Cráton do São Francisco. Revista Brasileira de Geociências, 4:349-364.

Baars F.J.; Matos G.M.; Abram M.B. 2003. Metalogenia Quantitativa do Brasil: Base do Conhecimento, Métodos e Exemplos. In: Bizzi L.A., Schobbenhaus C., Vidotti R.M., Gonçalves J.H. (ed.) Geologia, Tectônica e Recursos Minerais do Brasil: Texto, Mapas \& SIG. Brasília, CPRM, p. 440-499.

Babinski M., Brito-Neves B.B., Machado N., Noce C.M., Ulhein A., Van Schumus W.R. 1994. Problemas na metodologia $\mathrm{U} / \mathrm{Pb}$ em zircões de vulcânicas continentais: o caso do Grupo Rio dos Remédios, Supergrupo Espinhaço, no estado da Bahia. In: SBG, Congresso Brasileiro de Geologia, 38, Boletim de Resumos Expandidos, p. 409-410.

Babinski M., Pedreira A., Brito-Neves B.B., Van-Schmus W.R. 1999. Contribuição à geocronologia da Chapada Diamantina. In: SBG, Simpósio Nacional de Estudos Tectônicos, 7, Anais, p. 118-121.

Barbosa J.S.F \& Dominguez J.M.L (eds). 1996. Mapa Geológico do Estado da Bahia. Salvador, Superintendência de Geologia e Recursos Minerais, texto explicativo, escala: 1.000.000.

Barbosa J.S.F. \& Sabaté P. 2002. Geological feature and the paleoproterozoic od four archean crustal segments of the São Francisco Craton, Bahia, Brazil. A syntesis. An. Acad. Bras. Cienc., 2:343-359.

Bonham-Carter G.F. 1994. Geographic Information Systems for geoscientists: modelling with GIS. Computer methods in the geosciences, volume 13. Ontawa, Elsevier, 398 p. (Computer Methods in Geosciences, 13).

Brito D.C. 2008. Geologia, Petrografia e Litogeoquímica dos Diques Máficos que ocorrem na porção sudeste da Chapada Diamantina, Bahia, Brasil. Dissertação de Mestrado, Instituto de Geociências, Universidade Federal da Bahia, Salvador, 76 p.

Caby R. \& Arthaud M. 1987. Petrostrucutural evolution of the Lagoa Real subalcaline metaplutonic complex (Bahia, Brasil). Rev. Bras. Geoc., 17(4):636.

Chaves A.O., Trubrett M., Rios F.J., Oliveira L.A.R., Alves, J.V., Fuzikawa K., Neves J.M.C., Matos E.C., Chaves A.M.D.V., Plates S.P. 2007. U-Pb ages related to uraninum mineralization of Lagoa Real, Bahia-Brasil: tectonic implications. Revista de Geologia, 20(2):141156.

Chaves A.O., Tubrett M., Avelar S.C.P., Rios F.J., Sgarbi G.N.C., Correia Neves J.M., Alves J.V., Fuzikawa K., Matos E.C., Prates S.P. 2009. Electron microprobe chemical U-Th-Pb and La-ICP-MS U-Pb dating of multiple hydrothermal and metamorphic events recorded in minerals of the Lagoa Real uraniferous albitites (Brazil). Pesquisas em Geociências, 2:181-201.

Cordani U.G., Iyer S.S., Taylor P.N., Kawashita K., Sato K., McReath I. 1992. Pb-Pb, Rb-Sr, and K-Ar sistematic of the Lagoa Real uranium province (south-central Bahia, Brazil) and the Espinhaço Cycle (ca. 1.5-1.0 Ga). J. Sout. Amer. Eart. Sci., 1:33-46.

Costa P.H.O., Andrade A.R.F., Lopes G.A.C., Souza S.L. 1985. Projeto Lagoa Real. Salvador, CBPM/NUCLEBRAS/ SME, Mapeamento Geológico 1:25.000, 98 p.

Cruz S.C.P. 2004. A interação tectônica entre o Aulacógeno do Paramirim e o Orógeno Araçuai-Oeste Congo. Tese de Doutorado, Departamento de Geologia, Universidade Federal de Ouro Preto, Ouro Preto, 505 p.

Cruz S.C.P., Alkmim F.F., Leite C.M.M., Evangelista H.J., Cunha J.C., Matos E.C., Noce C.M., Marinho M.M. 2007. Geologia e arcabouço estrutural do Complexo lagoa 
Real, Vale do Paramirim, Centro-Oeste da Bahia. Revista Brasileira de Geociências, 37(4 - suplemento):128-146.

Cruz S.C., Carneiro M.A., Barbosa J.S.F., Martins A.A.M., Santana J.S., Tavares G.S.S.T., Menezes-Leal A.B., Dantas E., Pimentel M.M. (submetido). Novos dados geocronológicos do núcleo da anticlinal de AbaíraJussiape, Chapada Diamantina Ocidental, Bahia. Revista Brasileira de Geociências.

Cruz S.C.P. \& Alkmim F.F. 2006. The tectonic interactionbetween the Paramirim Aulacogen and the Araçuaí Belt, São Francisco Craton region, Easter Brazil. Anais da Academia Brasileira de Ciências, 1:151-173.

Danderfer A. \& Dardenne M.A. 2002. Tectonoestratigrafia da Bacia Espinhaço na porção centro-norte do Cráton do São Francisco: registro de uma evolução poliistórica descontínua. Rev. Bras. Geoc., 32(4):449-460.

Danderfer $\mathrm{F}^{\circ}$. A. 2000. Geologia sedimentar e evolução tectônica do Espinhaço Setentrional, estado da Bahia. Tese de Doutoramento, Instituto de Geociências, Universidade Federal de Brasília, Brasília, 497 p.

Danderfer A., De Waele B., Pedreira A., Nalini H.A. 2009. New geochronological constraints on the geological evolution of Espinhaço basin within the São Francisco Craton - Brazil. Precambrian Research, 170:116-128.

Franca-Rocha W.J.S. 2001. Modelagem metalogenética na bacia de Irecê (Ba) através de Sistemas de Informações Geográficas (SIG). Tese de Doutorado, Instituto de Geociências, Universidade Federal da Bahia, Salvador, $350 \mathrm{p}$.

Guimarães et al. 2005. Projeto Ibitiara - Rio de Contas. Salvador, CPRM/CBPM, Programa Recursos Minerais do Brasil, $182 \mathrm{p}$.

Guimarães J.T., Martins A.A.M., Andrade-Filho E.L., Loureiro H.S.C., Arcanho J.B.A., Neves J.P., Abram M.B., Silva M.G., Melo R.C., Bento R.V. (orgs.) 2005. Projeto Ibitiara-Rio de Contas. Estado da Bahia. Salvador, CPRM, $157 \mathrm{p}$.

Guimarães J., Torres, Santos R.A., Melo R.C. (org.). 2008. Geologia da Chapada Diamantina Ocidental (Projeto Ibitiara Rio de Contas). Salvador, CBPM, 64 p.

Lobato L.M. 1985. Metamorphism, metassomatism and mineralization at Lagoa Real, Bahia, Brazil. Tese de Doutoramento, University Western Ontario, Ontario, 306 p.

Lobato L. \& Fyfe W. 1990. Metamorphism and mineralization at Lagoa Real, Bahia, Brasil. Econ. Geol., 5:968-989.

Maruèjol P. 1989. Metasomatose alcalino et mineralization uraniferes: lês albitites du gisement de Lagoa Real (Bresil). Doctor of Philosophy Thesis, Centre de Recherches sur la Géologie de l'Uranium, Vandoeuvre-les-Nancy, 421 p.

Misi A. \& Veizer J. 1996. Chemostratigraphy of neoproterozoic carbonate sequences of the Una Group, Irecê Basin, Brazil. In: SBG/NBA-SE, Congresso Brasileiro de Geologia, 39, Anais, p. 487-489.

Moutinho da Costa L.A. \& Inda H.A.V. 1982. O Aulacógeno do Espinhaço. Ciências da Terra, 2:13-18.

Pedreira A.J.C.L. 1988. Seqüências deposicionais no PréCambriano: exemplo da Chapada Diamantina Oriental, Bahia. In: SBG, Congresso Brasileiro de Geologia, 33, Anais, p. 648-659.
Pedrosa-Soares A.C., Noce C.M., Wiedemann C.M., Pinto C.P. 2001. The Araçuaí-West-Congo Orogen in Brazil: an overview of a confined orogen formed during Gondwanaland assembly. Precamb. Res., 110(1-4):307323.

Pedrosa-Soares A.C., Noce C.M., Alkmim F.F., Silva L.C., Babinski M., Cordani U. Castañeda, C. 2007. Orógeno Araçuaí: síntese do conhecimento 30 anos após Almeida 1977. Geonomos, 1:1-16.

Perrota M.M. 1996. Potencial Aurífero de uma Região no Vale do Ribeira, São Paulo, Estimado por Modelagem de Dados Geológicos, Geoquímicos, Geofisicos e de Sensores Remotos num Sistema de Informações Geográficas. Tese de Doutorado, Instituto de Geociências, Universidade de São Paulo, São Paulo, 149 p.

PimentelM.M., MachadoN.,LobatoL.M.1994.Geocronologia $\mathrm{U} / \mathrm{Pb}$ de rochas graníticas e gnáissicas da região de Lagoa Real, Bahia, e implicações para a idade da mineralização de urânio. In: SBG, Congresso Brasileiro de Geologia, 38, Boletim de Resumos Expandidos, p. 389-390.

Schobbenhaus C. 1996. As tafrogêneses superpostas Espinhaço e Santo Onofre, estado da Bahia: Revisão e novas propostas. Rev. Bras. Geoc., 4:265-276.

Schobbenhaus C., Campos D.A., Derze G.R., Asmus H.E. 1981. Mapa Geológico do Brasil e da Área Oceânica Adjacente, Incluindo Depósitos Minerais. Brasília, DNPM, escala 1:2.500.000.

Schobbenhaus C., Hoppe A., Baumann A., Lork A. 1994. Idade $\mathrm{U} / \mathrm{Pb}$ do vulcanismo Rio dos Remédios, Chapada Diamantina, Bahia. In: SBG, Congresso Brasileiro de Geologia, 38, Anais, 2, p. 397-399.

Simpsom C. 1985. Deformation of granitic rocks across the brittle-ductile transition. Journ. Struct. Geol., 7:503-511.

Simpson C. 1986. Fabric development in brittle-to-ductile shear zones. Pure appl. Geophys, 124: 269-288.

Stipp M., Stünitz H., Heilbronner R., Schmid S.M. 2002. Dynamic ecrystallization of quartz: correlation between natural and experimental conditions. In: De Meer S., Drury M.R., De Bresser J.H.P., Pennock G.M. (eds.) Deformation Mechanisms, Rheology and Tectonics: Current Status and Future Perspectives. London, Geological Society, Special Publications 200, p. 171-190.

Tullis J. 1983. Deformation of feldspar. In: Ribbe, P.H. (ed.) Feldspar Mineralogy. Washington, Mineralogical Society of America, p. 297-323.

Vauchez A. 1987. The development of discret shear-zones in a granite: Stress, strain and changes in deformation mechanisms. Tectonophysics, 133:137-156.

Voll G. 1976. Recrystallization of quartz, biotite and feldspar from Erstfeld to the Leventina nappe, Swiss Alps, and its geological significance. Schweiz. Mineral. Petrogr. Mitt., 56:641-647.

Manuscrito ID 15167 Submetido em 24 de agosto de 2009 Aceito em 13 de dezembro de 2010 